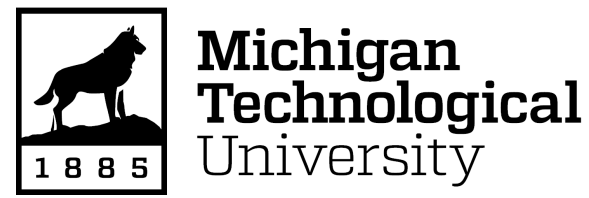

Michigan Technological University Digital Commons @ Michigan Tech

Dissertations, Master's Theses and Master's Reports

2022

\title{
Hardware In The Loop Implementation and Simulations of a Wave Energy Converter using Typhoon HIL and Speedgoat
}

Pranav Nair

Michigan Technological University, ponair@mtu.edu

Copyright 2022 Pranav Nair

\section{Recommended Citation}

Nair, Pranav, "Hardware In The Loop Implementation and Simulations of a Wave Energy Converter using Typhoon HIL and Speedgoat", Open Access Master's Report, Michigan Technological University, 2022.

https://doi.org/10.37099/mtu.dc.etdr/1350

Follow this and additional works at: https://digitalcommons.mtu.edu/etdr

Part of the Electrical and Electronics Commons, and the Power and Energy Commons 
HARDWARE IN THE LOOP IMPLEMENTATION AND SIMULATIONS OF A WAVE ENERGY CONVERTER USING TYPHOON HIL AND SPEEDGOAT

\author{
By \\ Pranav Nair
}

\begin{abstract}
A REPORT
Submitted in partial fulfillment of the requirements for the degree of MASTER OF SCIENCE

In Electrical Engineering
\end{abstract}

MICHIGAN TECHNOLOGICAL UNIVERSITY

2022

(C) 2022 Pranav Nair 

This report has been approved in partial fulfillment of the requirements for the Degree of MASTER OF SCIENCE in Electrical Engineering.

Department of Electrical and Computer Engineering

\author{
Report Advisor: Dr. Wayne W. Weaver \\ Committee Member: $\quad$ Dr. Gordon G. Parker \\ Committee Member: Prof. John T. Lukowski \\ Department Chair: Dr. Glen E. Archer
}





\section{Contents}

List of Figures $\ldots \ldots \ldots \ldots \ldots \ldots \ldots \ldots \ldots \ldots$

List of Tables ..................... xiii

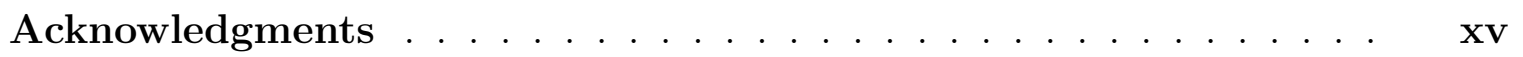

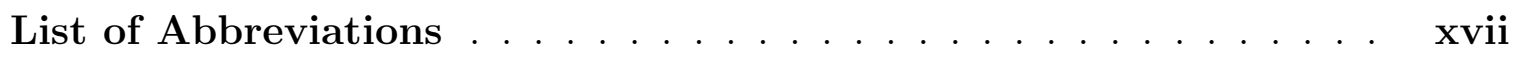

Abstract .......................

$1 \quad$ Introduction $\ldots \ldots \ldots \ldots \ldots \ldots \ldots \ldots \ldots \ldots \ldots \ldots \ldots$

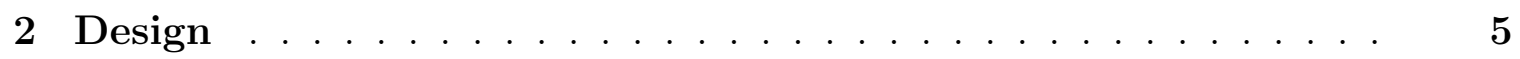

2.1 Mechanical Systems . . . . . . . . . . . . . . . . 6 G

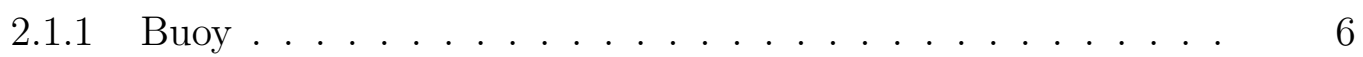

$2.1 .2 \quad$ Rack and Pinion $\ldots \ldots \ldots \ldots \ldots \ldots$

2.2 Electrical Systems . . . . . . . . . . . . . . . . . . 8

$2.2 .1 \quad$ DC Machine . . . . . . . . . . . . . . . . . . . . . 8

2.2.2 Power Electronics - Single Phase Inverter . . . . . . . . 12

2.2.3 Energy Storage System and Power Take-Off to the Grid . . 15 
2.3 Controls . . . . . . . . . . . . . . . . . . . . . . . . 19

2.3.1 PD control to maximize the wave power extraction $\ldots \ldots$

2.3 .2 Inverter control . . . . . . . . . . . . . . . 20

2.3.3 Grid reference feed-forward control . . . . . . . . . . . 21

3 Hardware In the Loop Implementation . . . . . . . . . . . 25

3.1 Typhoon HIL $\ldots \ldots \ldots \ldots$

3.1.1 Hardware and Setup . . . . . . . . . . . . 29

3.1 .2 Modeling Tools . . . . . . . . . . . . . . . . 30 30

3.1.2.1 Typhoon HIL Schematic Editor . . . . . . . . . 30

$3.1 .2 .2 \quad$ HIL SCADA $\ldots \ldots \ldots \ldots \ldots$

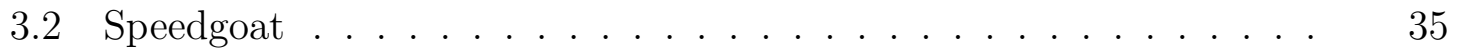

3.2 .1 Hardware and Setup . . . . . . . . . . . . . 35

3.2 .2 Modeling Tools . . . . . . . . . . . . . . . . . . 37

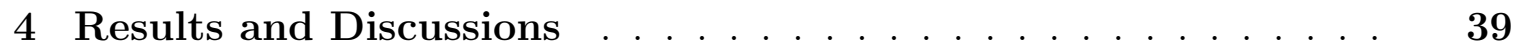

4.1 Preliminary WEC model results . . . . . . . . . . . . . 39

4.1.1 Single frequency wave test $\ldots \ldots \ldots \ldots \ldots$

4.1.2 Multiple frequency wave test . . . . . . . . . 49

4.2 Operating conditions of current model based on the update rate . . 59

4.2.1 Discussions about the operating condition of the current model 64

4.3 ESS energy requirement $\ldots \ldots \ldots \ldots \ldots \ldots$ 
5 Conclusion and Future Work

References ......................... 77 



\section{List of Figures}

2.1 Basic structure of a wave energy conversion setup . . . . . . . . 5

2.2 Typhoon HIL DC machine schematic . . . . . . . . . . . . 9

2.3 Typhoon HIL DC machine load parameter . . . . . . . . . . . . 11

2.4 Typhoon HIL single phase inverter schematic . . . . . . . . . . 12

2.5 Single phase inverter general representation . . . . . . . . 13

2.6 Single phase inverter setup for the study . . . . . . . . . . 14

2.7 ESS and PTO to the grid .............. 15

3.1 Hardware rack setup . . . . . . . . . . . . . . . 26

3.2 Hardware rack setup I/O's . . . . . . . . . . . . 27

$3.3 \mathrm{I} / \mathrm{O}$ wiring schematic . . . . . . . . . . . . . 29

3.4 Typhoon HIL Library Browser . . . . . . . . . . . . . . . . 31

3.5 Typhoon HIL Schematic Editor environment . . . . . . . . . . 32

3.6 HIL SCADA testing panel . . . . . . . . . . . . . . . 34

3.7 IO183 models from Simulink Real-Time library . . . . . . . . . 36

3.8 Simulation mode setup . . . . . . . . . . . . . . 37

3.9 Model code generation settings . . . . . . . . . . . . . . 38 
3.10 Model real-time target configuration settings . . . . . . . . . . .

4.1 Linear forces on the buoy - single frequency . . . . . . . . . 40

4.2 Linear vertical position of the buoy - single frequency . . . . . . . 41

4.3 Linear vertical velocity of the buoy - single frequency . . . . . . 41

4.4 Speed of the DC machine - single frequency $\ldots \ldots \ldots \ldots$

4.5 DC machine reference and actual torque - single frequency . . . . 43

4.6 Modulation signal for inverter control - single frequency . . . . . . . 44

4.7 Torque variation $\ldots \ldots \ldots \ldots \ldots \ldots \ldots$

4.8 Current from the WEC drive - single frequency . . . . . . . . 46

4.9 Bus voltage for $\tau_{f f}=1 \mathrm{~s}$ case - single frequency $\ldots \ldots \ldots$

4.10 Powers in the WEC system for $\tau_{f f}=1 \mathrm{~s}$ - single frequency $\ldots . .47$

4.11 Currents in the WEC system for $\tau_{f f}=1 \mathrm{~s}$ - single frequency $\ldots$.

4.12 Linear forces on the buoy - multi-frequency . . . . . . . . . 50

4.13 Linear vertical position of the buoy - multi-frequency . . . . . . 51

4.14 Linear vertical velocity of the buoy - multi-frequency $\ldots \ldots \ldots$

4.15 Speed of the DC machine - multi-frequency . . . . . . . . 52

4.16 Reference and the actual torque of the DC machine - multi-frequency 53

4.17 Modulation signal for inverter control - multi-frequency . . . . . 54

4.18 Current from the WEC drive - multi-frequency . . . . . . . . 54

4.19 Bus voltage for $\tau_{f f}=1 \mathrm{~s}$ case - multi-frequency $\ldots \ldots \ldots$

4.20 Powers in the WEC system for $\tau_{f f}=1 \mathrm{~s}$ - multi-frequency . . . 56 
4.21 Currents in the WEC system for $\tau_{f f}=1 \mathrm{~s}-$ multi-frequency . . . .

4.22 Bus voltage trend w.r.t update rate - 20 s wave period . . . . . 59

4.23 Bus voltage trend w.r.t update rate close to $5 \mathrm{~s}-20 \mathrm{~s}$ wave period . 61

4.24 Efficiency w.r.t update rate - $20 \mathrm{~s}$ wave period . . . . . . . . 62

4.25 Efficiency w.r.t update rate close to $5 \mathrm{~s}-20 \mathrm{~s}$ wave period . . . . 62

4.26 Max ESS power w.r.t update rate - $20 \mathrm{~s}$ wave period . . . . . 63

4.27 ESS energy required w.r.t update rate - $20 \mathrm{~s}$ wave period . . . . . 64

4.28 Currents at $\tau_{f f}=5 \mathrm{~s} \ldots \ldots \ldots \ldots$

4.29 Comparing ESS energy for single and multi-frequency tests . . . . . 67 



\section{List of Tables}

2.1 Mass-spring-damper parameter values . . . . . . . . . . . . . . . . 7

2.2 DC machine electrical parameters . . . . . . . . . . . 10

2.3 DC machine mechanical parameters . . . . . . . . . . 11

2.4 Parameters for the ESS and PTO circuit model . . . . . . . . 16

2.5 Variables for the ESS and PTO circuit model . . . . . . . . 16

2.6 Variables for the grid reference control model . . . . . . . . . 21

3.1 Hardware I/O wiring - Speedgoat 1 - mechanical sub-system . . . . 28

3.2 Hardware I/O wiring - Speedgoat 2 - controls sub-system . . . . . 28

3.3 Hardware I/O wiring - Typhoon HIL 604 - electrical sub-system . . 28 



\section{Acknowledgments}

It has been exhilarating and challenging to pursue a Master's degree at the Michigan Technological University. It encouraged me to push past my limits and gave me a whole new perspective on approaching and solving challenges. Several people were instrumental in my success.

First and foremost, I extend my sincere gratitude to my advisor Dr. Wayne W. Weaver, for his patience throughout the process, leading me through this process, providing me with all the resources and believing in my abilities. I would also like to thank my committee members, Dr. Gordon G. Parker and Prof. John T. Lukowski, for taking out the time and effort to improve my work.

Finally, I owe a debt of gratitude to all of my friends, family, and teachers for their unwavering support in all of my decisions. 



\section{List of Abbreviations}

\begin{tabular}{|c|c|}
\hline MRES & Marine Renewable Energy Sources \\
\hline WEC & Wave Energy Converter \\
\hline HIL & Hardware In the Loop \\
\hline GWh & Gigawatt hour \\
\hline TWh/yr & Terawatt hour per year \\
\hline MW & Megawatts \\
\hline $\mathrm{AC}$ & Alternating Current \\
\hline $\mathrm{DC}$ & Direct Current \\
\hline PTO & Power Take-Off \\
\hline ESS & Energy Storage System \\
\hline PWM & Pulse Width Modulation \\
\hline RL & Resistor-Inductor \\
\hline $\mathrm{RC}$ & Resistor-Capacitor \\
\hline AWG & American Wire Gauge \\
\hline $\mathrm{PD}$ & Proportional-Derivative \\
\hline PI & Proportional-Integral \\
\hline $\mathrm{DC}$ & Duty Cycle \\
\hline $\mathrm{I} / \mathrm{O}$ & Input-Output \\
\hline
\end{tabular}


PC Personal Computer

USB Universal Serial Bus

SCADA Supervisory Control and Data Acquisition

IDE Integrated Development Environment

w.r.t with respect to

$\tau_{f f} \quad$ update rate 


\section{Abstract}

Several studies have indicated that electricity production is the prime source of greenhouse emissions, more than flying and driving combined. Hence, over the past few decades, there has been a significant rise in the need for clean energy to achieve the targets in emissions reduction. It has been observed that the share of renewable energy sources in the percentage of total electricity production is rising, but, according to climate experts, the transition needs to speed up. Hence, it is significant to study and develop underutilized renewable energy sources.

One of these underutilized renewable energy sources is wave energy. It has been observed that wave energy is a source with very high potential and predictability but has been in the nascent development stage for a while now due to several technical challenges. One of them is the limitation in studying all the real-world scenarios in a laboratory and the cost of up-scaling it to the real world. A low-cost, efficient solution to study and validate such technologies is Hardware In the Loop (HIL) implementation.

In this study, an attempt has been made to develop a systematic wave energy converter (WEC) model using Typhoon HIL and Speedgoat. The developed model can act as a universal model to pick, study, test, and validate the individual components 
of the WEC in the HIL environment. Preliminary results show a reasonable trend in the behavior of the WEC. WEC system behavior for both single and multi-frequency wave tests has been discussed in the report. The stability/operating conditions for the current model configuration and a few insights on the energy storage system have also been discussed. 


\section{Chapter 1}

\section{Introduction}

Renewable energy technologies are the future. As per the assessment by the International Renewable Energy Agency (IRENA), deploying renewable energy sources at a higher rate would bring down emissions by $90 \%$ by 2050 [1]. The global energy consumption in 2040 is predicted to be higher by 30\% than the one in 2010 [2] hence; there is a constant need to develop and study the existing underutilized renewable energy sources.

One of these energy sources is the Marine Renewable Energy Sources (MRES), including both tidal and wave energy. It has been observed that MRES are one of the significant untapped energy sources with a theoretical potential of about 151300 TWh/yr [3]. Due to technical and economic difficulties, most of the projects in 
this renewable energy sector have been small-scale demonstrations with a capacity of about 1 MW compared to other renewable energy technologies. However, compared to wave energy, using mature tidal turbine technologies, tidal energy extraction has been demonstrating higher reliability due to lower complexities in power extraction. It has surpassed a total generation of $60 \mathrm{GWh}$ in 2020 [4].

The most significant technical challenge in WEC technology is conducting studies in a laboratory environment. The scenarios demonstrated in a laboratory are highly controlled compared to real-world scenarios. Considering the economic challenges to up-scale a laboratory tested WEC technology to the real world with several unpredictable scenarios, the capital, time, and resources required are very high [5]. An economically viable and technically accurate option to tackle these challenges is implementing, testing, and validating these systems using HIL technologies.

The past few decades have seen an exponential rise in the available computational power. Hence, the use of simulations in testing the products has also increased. In parallel with this trend, using HIL devices with such simulations for rapid prototyping and validation of complex engineering systems has also seen a rise [6]. Various historical references to different kinds of HIL simulators used in flight testing, vehicle testing are available in the literature [7]. 8] defines a HIL simulator as "a setup that emulates a system by immersing faithful physical replicas of some of its subsystems 
within a closed-loop virtual simulation of the remaining subsystems." Some advantages of HIL systems over other ways of product development are cost-effectiveness, repeatability, comprehensiveness, safety, and concurrent systems engineering [8].

For complex and expensive engineering systems like WECs, HIL simulations are highly appropriate. This study attempted to develop a systematic HIL model for a WEC. While modeling, the WEC system was segmented into individual mechanical, electrical, and control components. Segmenting the model makes studying individual components easier and implementing the improvements effortlessly into the large-scale model.

This report has been divided into three sections. The first part of the report explains the design process of the mechanical, electrical, and control subsystems for the WEC. Secondly, the report details the setup of the HIL devices and the model implementation, testing, and data acquisition using Typhoon HIL and Speedgoat devices. The final part of the report is focused on the analysis and discussions of the acquired data. 


\section{Chapter 2}

\section{Design}

The basic structure of a wave energy conversion setup is shown in Figure 2.1.

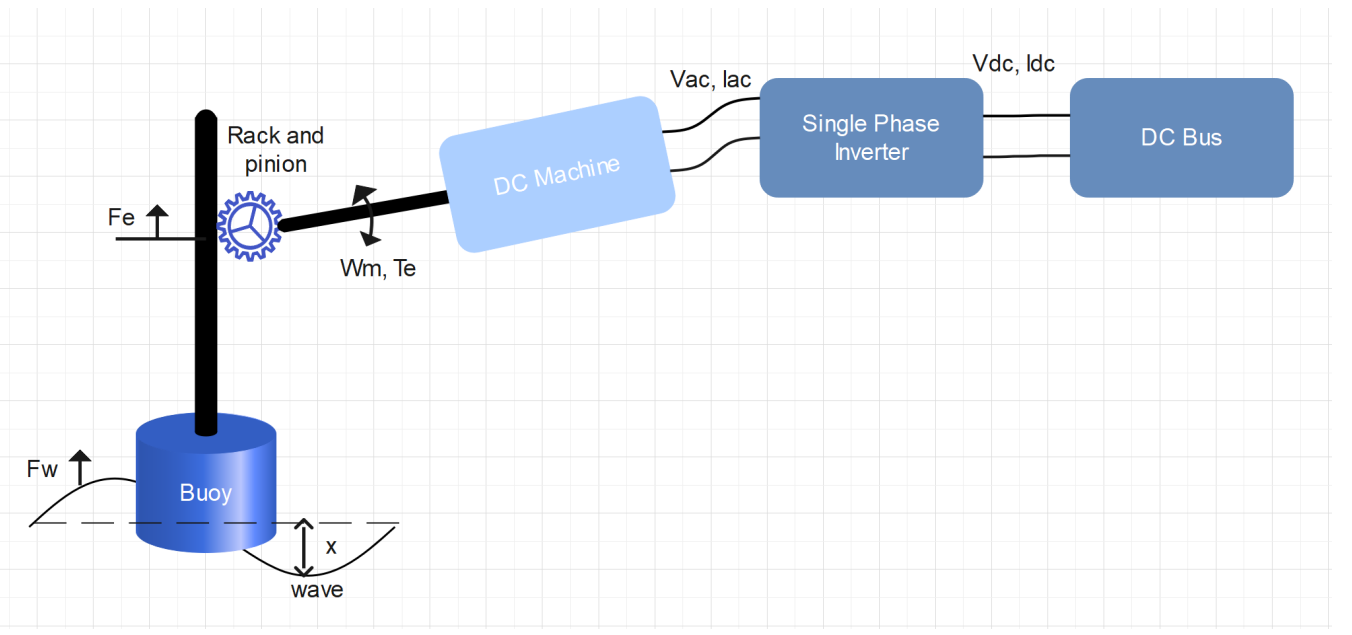

Figure 2.1: Basic structure of a wave energy conversion setup

The wave force generates a vertical linear motion of the buoy. This vertical linear motion is then converted into a rotational motion by a rack and pinion gear system. 
This rotational motion in terms of motor speed/torque acts as a load to the DC machine. Then, the machine generates AC power, then converts it to DC power through a single-phase inverter.

\subsection{Mechanical Systems}

\subsubsection{Buoy}

The buoy has been modeled as a simple mass-spring-damper system for this study. The equation of motion for this system is shown as

$$
\Sigma F=M \ddot{x}+C \dot{x}+K x .
$$

The forces considered in the system are the wave force $\left(\mathrm{F}_{w}(\Omega)\right)$, where $\Omega$ is the wave frequency and the actuator force $\left(\mathrm{F}_{\mathrm{e}}\right)$. Substituting these terms into 2.1, the result is

$$
F_{w}(\Omega)+F_{e}=M \ddot{x}+C \dot{x}+K x .
$$

where, $x(\mathrm{~m})$ is the position of the buoy, $\dot{x}(\mathrm{~m} / \mathrm{s})$ is the velocity of the buoy and $\ddot{x}$ 
$\left(\mathrm{m} / \mathrm{s}^{2}\right)$ is the acceleration of the buoy. The values considered for the mass-springdamper coefficients for this study are shown in Table 2.1.

Table 2.1

Mass-spring-damper parameter values

\begin{tabular}{lll}
\hline Parameter & \multicolumn{1}{c}{ Description } & \multicolumn{1}{c}{ Value } \\
\hline $\mathrm{M}$ & Mass of the buoy & $268 \mathrm{~kg}$ \\
$\mathrm{C}$ & Damper coefficient & $1226 \mathrm{Ns} / \mathrm{m}$ \\
$\mathrm{K}$ & Spring constant & $1194 \mathrm{~N} / \mathrm{m}$ \\
\hline
\end{tabular}

\subsubsection{Rack and Pinion}

The rack and pinion gearing system converts the vertical linear motion of the buoy to rotational motion. Gear radius is an important parameter when translating the linear velocity into rotational velocity. This process is governed by

$$
\dot{x}=v=r \omega_{m} .
$$

This study has not considered the static and viscous friction losses in the rack and

pinion gear system. The gear radius was considered to be $0.047 \mathrm{~m}$. The gearing system can be sized using the values of the maximum linear and the rotational velocity as 


$$
r=\frac{\dot{x}_{\max }}{\omega_{m, \max }}=\frac{v_{\max }}{\omega_{m, \max }}
$$

where, $r(\mathrm{~m})$ is the gear radius, $v$ and $\dot{x}(\mathrm{~m} / \mathrm{s})$ is the velocity of the buoy, $\dot{x}_{\max }$ and $v_{\max }(\mathrm{m} / \mathrm{s})$ is the maximum velocity of the buoy, $\omega_{m}(\mathrm{rad} / \mathrm{s})$ is rotational speed of the DC machine and $\omega_{m, \max }(\mathrm{rad} / \mathrm{s})$ is the maximum rotational speed of the DC machine.

\subsection{Electrical Systems}

\subsubsection{Machine}

The DC machine model available in Typhoon HIL library is a separately excited DC machine, and this model has been used in this study [9]. The model schematic as

seen in the Typhoon HIL Schematic editor can be seen in the Figure 2.2. F1 and F2 are the field (stator) winding terminals, and A1 and A2 are the armature (rotor) field windings.

The system of equations governing the electrical part of the DC machine is shown below in the (2.5), 2.6), 2.7) and (2.8). The electrical parameters represented with the subscript $a$ indicate the armature part, and those with the subscript $f$ indicate the field part of the DC machine. The armature and field voltage is computed as 


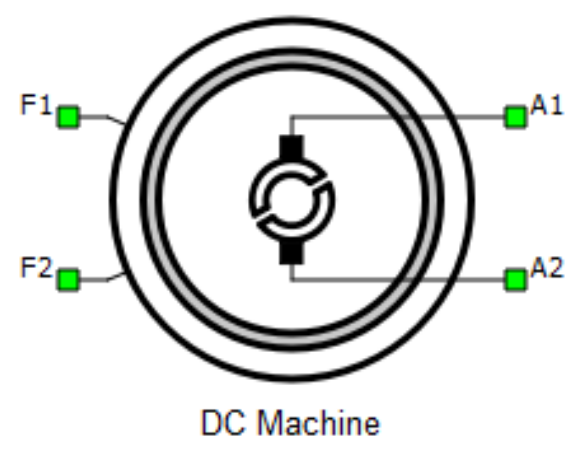

Figure 2.2: Typhoon HIL DC machine schematic

$$
\left[\begin{array}{c}
v_{a} \\
v_{f}
\end{array}\right]=\left[\begin{array}{cc}
R_{a} & 0 \\
0 & R_{f}
\end{array}\right]\left[\begin{array}{c}
i_{a} \\
i_{f}
\end{array}\right]+\frac{d}{d t}\left[\begin{array}{c}
\psi_{a} \\
\psi_{f}
\end{array}\right]+\left[\begin{array}{c}
\omega_{r} \psi \\
0
\end{array}\right] .
$$

The armature and field winding flux can be computed as

$$
\left[\begin{array}{l}
\psi_{a} \\
\psi_{f}
\end{array}\right]=\left[\begin{array}{cc}
L_{a} & 0 \\
0 & L_{f}
\end{array}\right]\left[\begin{array}{l}
i_{a} \\
i_{f}
\end{array}\right]
$$

The motor flux linkage is governed by

$$
\psi=L_{a f} i_{f}
$$

The electrical torque of the machine is given by 


$$
T_{e}=\psi i_{a} .
$$

The parameter values used for the electrical parameters of the DC machine were computed using (2.5), 2.6), 2.7), 2.8) and are given in Table 2.2.

Table 2.2

DC machine electrical parameters

\begin{tabular}{lll}
\hline Parameter & \multicolumn{1}{c}{ Description } & \multicolumn{1}{c}{ Value } \\
\hline $\mathrm{R}_{a}$ & Armature winding resistance & $0.01 \Omega$ \\
$\mathrm{R}_{f}$ & Field winding resistance & $25 \Omega$ \\
$\mathrm{L}_{a}$ & Armature winding inductance & $0.01 \mathrm{H}$ \\
$\mathrm{L}_{f}$ & Field winding inductance & $0.01 \mathrm{H}$ \\
$\mathrm{L}_{a f}$ & Mutual inductance between the armature and field windings & $0.165 \mathrm{H}$ \\
$\mathrm{V}_{f}$ & Field voltage & $150 \mathrm{~V}$ \\
\hline
\end{tabular}

The motion equation for the mechanical part of the DC machine is such that

$$
\frac{d \omega_{m}}{d t}=\frac{1}{J_{m}}\left(T_{e}-T_{l}-b \omega_{m}\right)
$$

and

$$
\theta_{m}=\int \omega_{m} d t .
$$

The parameter values used for the mechanical parameters of the DC machine are shown in Table 2.3 
Table 2.3

DC machine mechanical parameters

\begin{tabular}{lll}
\hline \multicolumn{1}{c}{ Parameter } & \multicolumn{1}{c}{ Description } & \multicolumn{1}{c}{ Value } \\
\hline $\mathrm{Jm}$ & Combined rotor and load moment of inertia & $0.02215 \mathrm{~kg} \cdot \mathrm{m}^{2}$ \\
$\mathrm{~b}$ & Machine viscous friction coefficient & $0 \mathrm{Nms}$ \\
Unconstrained Limiting mechanical angle between 0 and 2 $\pi$ & disabled \\
mechanical & & \\
angle & & \\
\hline
\end{tabular}

The following important parameter in the DC machine setup is the load applied to the machine. Typhoon HIL gives the load to the motor through the model or an external pin. This study applied a speed load to the motor from the model environment. Figure 2.3 shows how the motor load parameter was set up in the Typhoon HIL Schematic Editor.

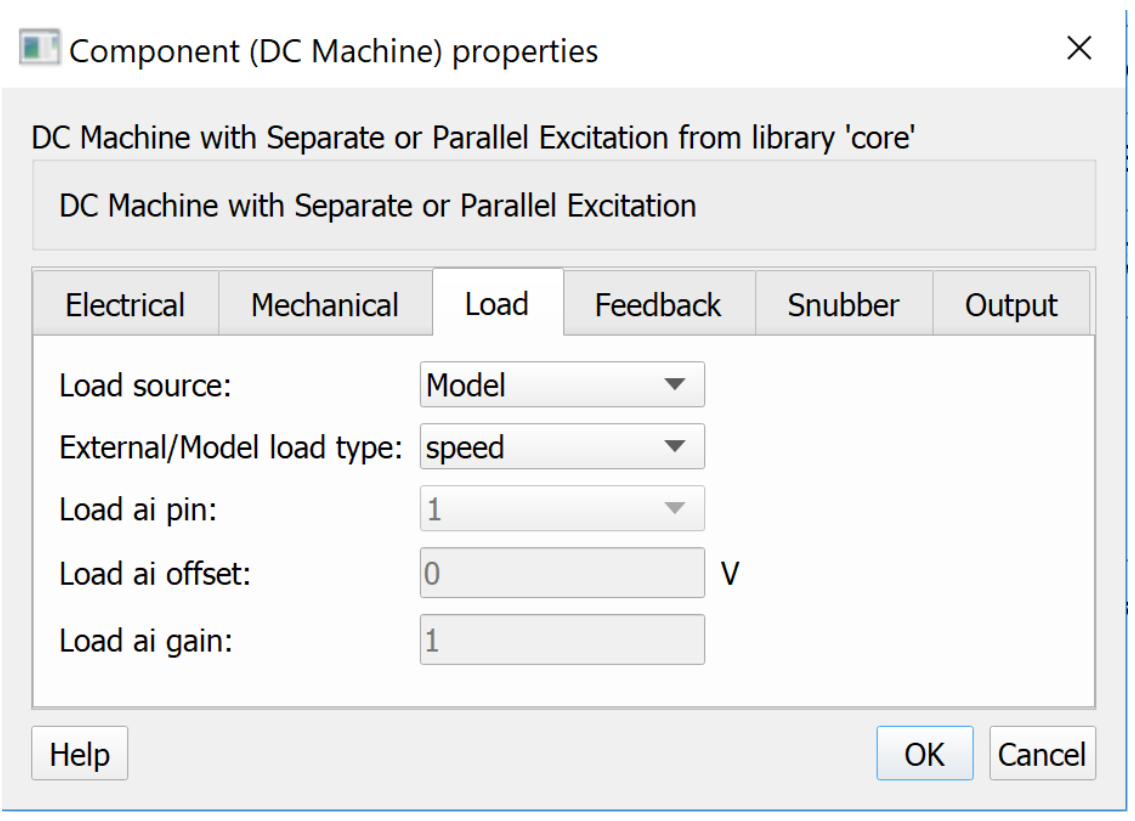

Figure 2.3: Typhoon HIL DC machine load parameter 


\subsubsection{Power Electronics - Single Phase Inverter}

A single-phase inverter is used to convert the AC power to DC power in this system. The single-phase inverter model available in the Typhoon HIL library has been used in this study [9]. The switches and diodes used in this model are ideal, and the losses are not considered. The model schematic as seen in the Typhoon HIL Schematic editor can be seen in the Figure 2.4. The general internal representation of a single-phase inverter as shown in [9] can also be seen below in Figure 2.5 .

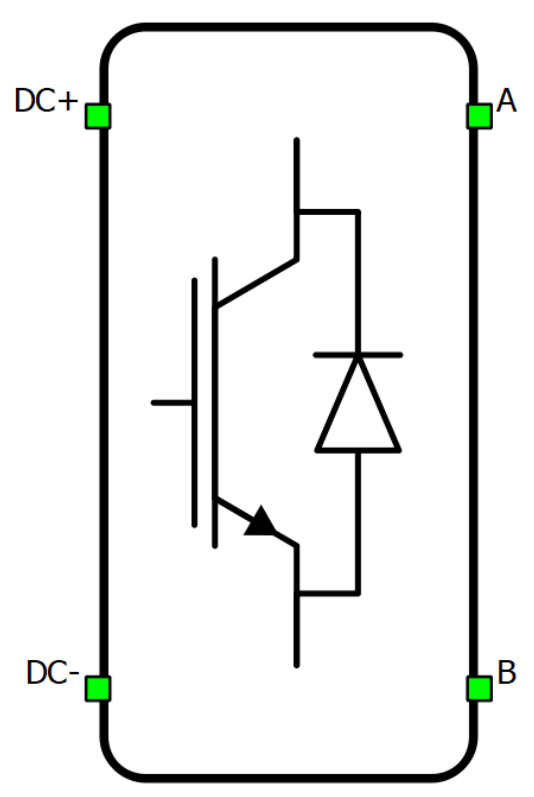

Figure 2.4: Typhoon HIL single phase inverter schematic

There are multiple options available in Typhoon HIL to control the inverter module. The first option is to provide switching signals to the individual inverter switches/legs through external hardware and pins. Another option is using the internal modulator 


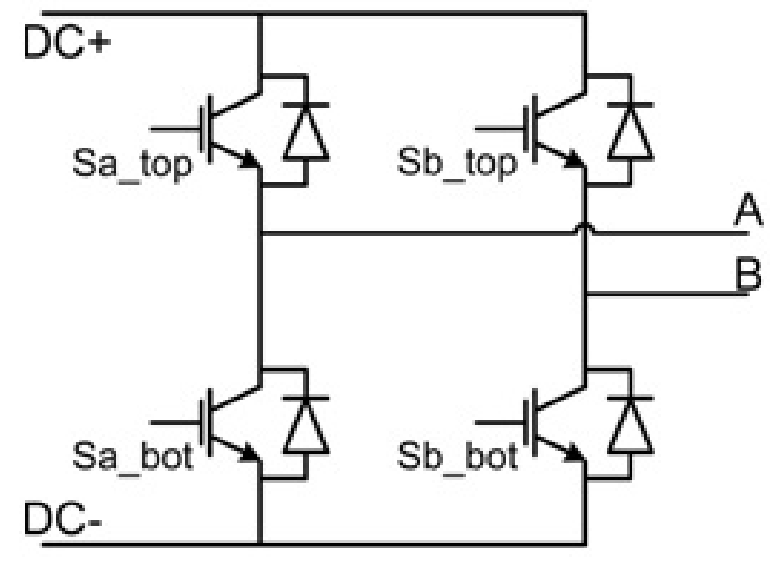

Figure 2.5: Single phase inverter general representation

to modulate the PWM switching signals based on the reference signals provided through the model. This study uses the latter, and the generation of the reference signals is explained in section 2.3.2. 
The inverter set up for this study is seen in Figure 2.6. An internal modulator was used to generate the PWM switching signals based on the reference signal in the range of $0-1$. This means that when the reference signal is 0.5 , both the legs of inverter switches conduct for $50 \%$ of the time period (duty cycle of 50\%). All the other parameters are discussed in detail under PWM modulator in [9].

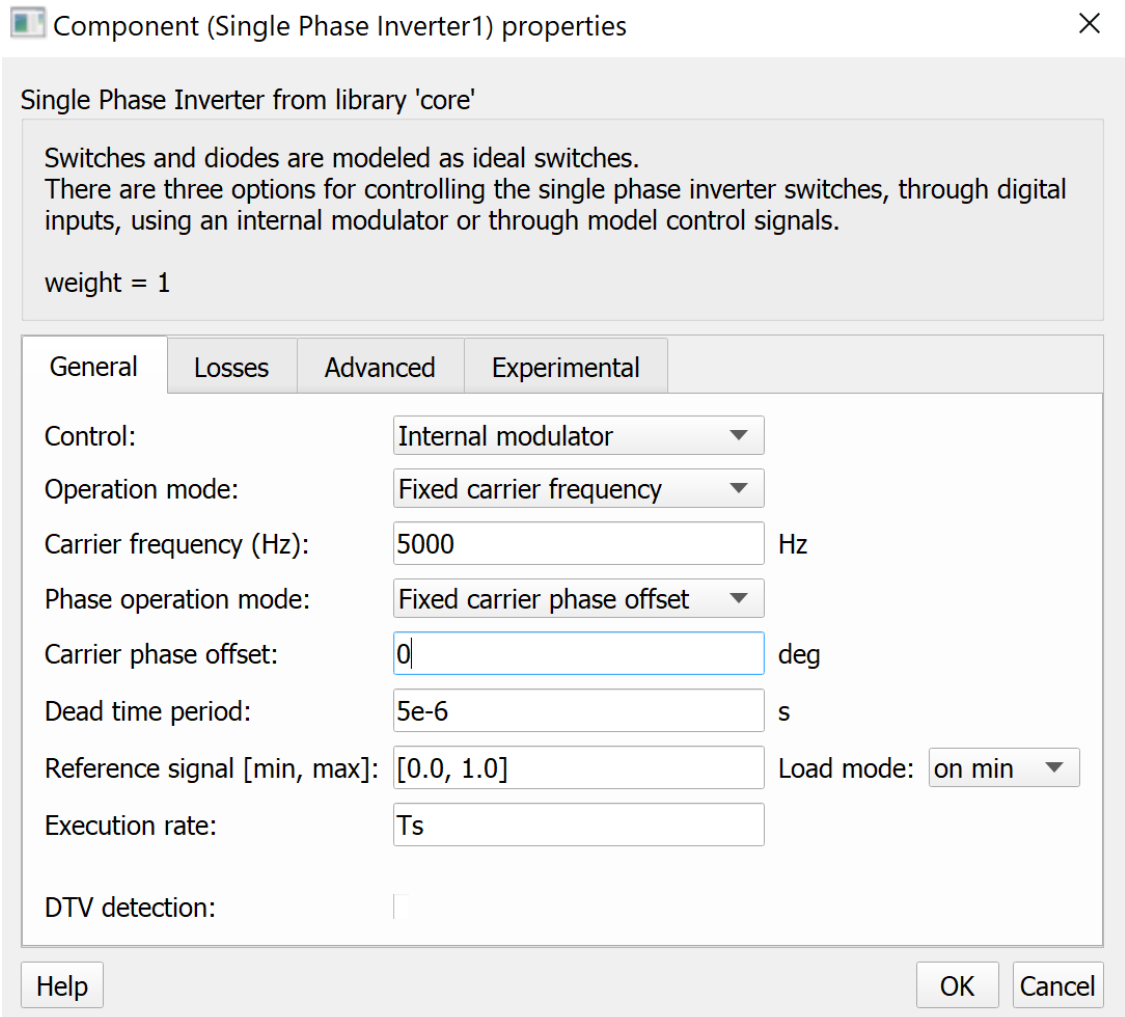

Figure 2.6: Single phase inverter setup for the study 


\subsubsection{Energy Storage System and Power Take-Off to the Grid}

The basic structure of the WEC as shown in Figure 2.1 is simplified and does not include the power take-off to the grid. However, designing the power take-off is very important to study the scope of a renewable energy source. The design for power take-off is incorporated from [10]. The design for power take-off can be seen in Figure 2.7 .

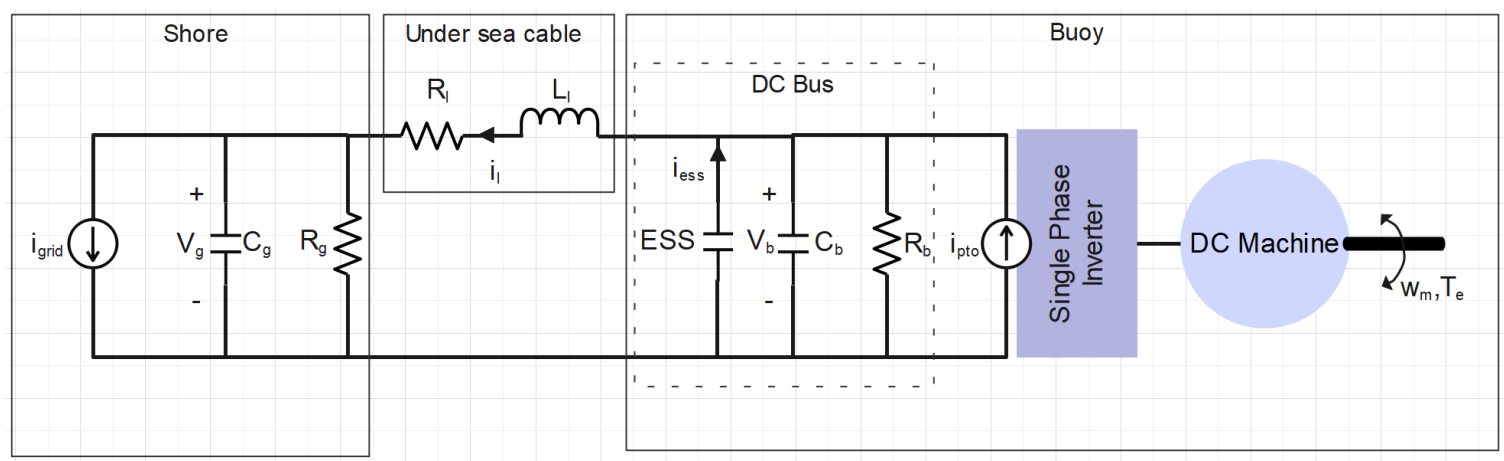

Figure 2.7: ESS and PTO to the grid

The model of the system for power take-off is shown

$$
\begin{gathered}
C_{b} \frac{d V_{b}}{d t}=i_{p t o}-\frac{V_{b}}{R_{b}}-i_{e s s}-i_{l} . \\
L_{l} \frac{d i_{l}}{d t}=V_{b}-i_{l} R_{l}-V_{g} . \\
C_{g} \frac{d V_{g}}{d t}=i_{l}-i_{g r i d}-\frac{V_{g}}{R_{g}} .
\end{gathered}
$$


The model variables and the parameter values used are shown in the Tables 2.4 and 2.5 respectively [10].

Table 2.4

Parameters for the ESS and PTO circuit model

\begin{tabular}{lll}
\hline Parameter & \multicolumn{1}{c}{ Description } & \multicolumn{1}{c}{ Value } \\
\hline $\mathrm{R}_{b}$ & Bus Parasitic Resistance & $1000 \Omega$ \\
$\mathrm{R}_{g}$ & Grid Inverter Resistance & $1000 \Omega$ \\
$\mathrm{C}_{b}$ & Bus Capacitance & $2 \mu \mathrm{F}$ \\
$\mathrm{C}_{g}$ & Grid Inverter Capacitance & $2 \mu \mathrm{F}$ \\
$\mathrm{R}_{l}$ & Under sea cable inductance & $2.5 \Omega$ \\
$\mathrm{L}_{l}$ & Under sea cable inductance & $95.6 \mu \mathrm{H}$ \\
\hline
\end{tabular}

Table 2.5

Variables for the ESS and PTO circuit model

\begin{tabular}{ll}
\hline Parameter & \multicolumn{1}{c}{ Description } \\
\hline $\mathrm{i}_{\text {pto }}$ & Current from the WEC drive (A) \\
$\mathrm{i}_{\text {ess }}$ & Current from the ESS $(\mathrm{A})$ \\
$\mathrm{i}_{\text {grid }}$ & Current drawn into the grid $(\mathrm{A})$ \\
$\mathrm{i}_{l}$ & Current in the under sea cable $(\mathrm{A})$ \\
$\mathrm{V}_{b}$ & Bus voltage $(\mathrm{V})$ \\
$\mathrm{V}_{g}$ & Grid-side voltage $(\mathrm{V})$ \\
\hline
\end{tabular}

ESS requirements for the WEC system are relatively small [10]. Passive supercapacitor systems can act as the ESS. Having a supercapacitor bank on the buoy also helps in direct filtering of the DC power, and an active DC-DC converter is not required [10]. In [10], the ESS has been emulated as a current source with PI control which assumes that the ESS has infinite energy to stabilize the bus, but, in this study, a supercapacitor model available in the Typhoon HIL library has been used [9]. This 
can provide a better overview of how the ESS would behave in the WEC system.

The undersea cable used to transmit the power from the buoy to the shore has been modeled as a series RL circuit. A 6 AWG, $1 \mathrm{~km}$ cable has been considered. The equations governing the parameter design for the undersea cable can be seen in 2.14 and 2.15) [11].

$$
\begin{gathered}
L_{l}=\frac{\mu_{o} \mu_{r}}{\pi} \cosh ^{-1}\left(\frac{s}{d}\right)(\text { length of the cable }) . \\
R_{l}=(\text { DC resistance of the cable })(\text { length of the cable })(2) .
\end{gathered}
$$

where the values of the parameters used to compute $\mathrm{L}_{1}$ and $\mathrm{R}_{1}$ shown in Table 2.4 are, permeability of free space $\left(\mu_{o}=4 \pi e^{-7} \mathrm{H} / \mathrm{m}\right)$, relative permeability $\left(\mu_{r}=1 \mathrm{H} / \mathrm{m}\right)$, distance between the conductors $(\mathrm{s}=4.115 \mathrm{~mm})$, diameter of the conductors $(\mathrm{d}=4$ $\mathrm{mm}$ ), length of the cable $=1 \mathrm{~km}=1000 \mathrm{~m}$, DC resistance of a 6 AWG copper cable $=1.25 \mathrm{~m} \Omega / \mathrm{m}$.

A grid side inverter has been realized using an $\mathrm{RC}$ circuit on the shore side. The power injected into the grid is emulated by a current source $i_{\text {grid }}$. There is a specific control structure implemented to update the power command to the grid through 
changing the reference $i_{\text {grid }}$ current value. It has been explained in detail in section 2.3 .3 


\subsection{Controls}

\subsubsection{PD control to maximize the wave power extraction}

A PD control is implemented for the actuator force $\left(\mathrm{F}_{\mathrm{e}}\right)$ to generate an $\mathrm{F}_{\text {eref }}$ such that maximum power is extracted from the wave force $\left(\mathrm{F}_{\mathrm{w}}(\Omega)\right)[12$. The equation governing this control is shown

$$
F_{e, r e f}=-k_{p, p d} x-k_{d, p d} \dot{x}
$$

The gains were computed to match the impedance of the system as

$$
\begin{gathered}
k_{p, p d}=M \Omega^{2}-K . \\
k_{d, p d}=C .
\end{gathered}
$$

where, $k_{p, p d}$ is the proportional gain and $k_{d, p d}$ is the derivative gain used here. The values of $\mathrm{M}, \mathrm{C}$, and $\mathrm{K}$ used are given in Table 2.1. 


\subsubsection{Inverter control}

Inverter control determines the modulation signal provided to the inverter. The modulation signal determines the switching of the inverter switches through the internal modulator. From the $\mathrm{F}_{\mathrm{e}, \text { ref }}$ computed in the $\mathrm{PD}$ control, using the gear radius, a reference torque is generated. The reference torque is compared with the present torque of the machine. Then, a control action is initiated through a PI controller to determine the modulation signal. The controller gains are tuned to be $\mathrm{k}_{\mathrm{p}, \mathrm{inv}}=0.01$ and $\mathrm{k}_{\mathrm{i}, \mathrm{inv}}=$ 0.05 by analyzing the error between the machine torque and the computed reference torque. The modulation signal is limited to a range of $0-1$. The action of this control can be explained through (2.19) and 2.20 .

$$
\begin{gathered}
\tilde{T}_{e}=T_{e, r e f}-T_{e} . \\
\text { Modulation signal }=k_{p, i n v} \tilde{T}_{e}+k_{i, i n v} \int \tilde{T}_{e} d t .
\end{gathered}
$$

where, $k_{p, i n v}$ is the proportional gain and $k_{i, i n v}$ is the integral gain. 


\subsubsection{Grid reference feed-forward control}

The model variables used to design the control can be seen in Table 2.6. The reference bus voltage is set at $200 \mathrm{~V}$ during this study. As mentioned in section 2.2.3, the grid side on the shore is realized using a current source $\left(\mathrm{i}_{\text {grid }}\right)$ and an $\mathrm{RC}$ circuit. The power export from the WEC to the grid is performed through this control.

Table 2.6

Variables for the grid reference control model

\begin{tabular}{ll}
\hline Parameter & \multicolumn{1}{c}{ Description } \\
\hline $\mathrm{i}_{\text {pto }}$ & Current from the WEC drive (A) \\
$\mathrm{i}_{l, r e f}$ & Reference undersea cable current (A) \\
$\mathrm{i}_{g, r e f}$ & Reference grid current $(\mathrm{A})$ \\
$\mathrm{V}_{b, r e f}$ & Reference bus voltage $(\mathrm{V})$ \\
$\mathrm{V}_{g, r e f}$ & Reference grid voltage $(\mathrm{V})$ \\
\hline
\end{tabular}

Continuously updating the power export command is ideal, but it poses challenges due to the inverter and communication difficulties. Hence, a concept of update rate $\left(\tau_{f f}\right)$ has been introduced. $\tau_{f f}$ is the rate at which the grid power export is updated through the update of reference grid current ( $\left.\mathrm{i}_{\mathrm{g}, \mathrm{ref}}\right)$. Basic Kirchoff's laws are used to compute the reference grid current. The process used to compute the reference grid current $\left(\mathrm{i}_{\mathrm{g}, \mathrm{ref}}\right)$ can be seen below [10].

Analyzing the circuit from the bus side to the shore side, a reference undersea cable 
current is computed by reducing the bus side parasitic losses from the WEC drive current

$$
i_{l, r e f}=i_{p t o}-\frac{V_{b, r e f}}{R_{b}} .
$$

Then, the grid side reference voltage is computed by reducing the undersea cable transmission voltage drop from the reference bus voltage

$$
V_{g, r e f}=V_{b, r e f}-i_{l, r e f} R_{l}
$$

On the grid side, the losses due to the grid side inverter resistance is reduced from the incoming undersea cable reference current to compute the reference grid current

$$
i_{g, r e f}=i_{l, r e f}-\frac{V_{g, r e f}}{R_{g}} .
$$

Combining all the above equations as

$$
i_{g, r e f}=i_{p t o}\left(1+\frac{R_{l}}{R_{g}}\right)-V_{b, r e f}\left(\frac{R_{b}+R_{g}+R_{l}}{R_{b} R_{g}}\right) .
$$


The update rate parameter $\tau_{f f}$ was realized using a zero-order hold. Zero order hold block is available in Simulink under Discrete library [13]. It was required that the grid demand was updated at a specific sample period. This block works as a switch which holds the current value for a specified sample period (update rate) and then updates it periodically. The effect and significance of $\tau_{f f}$ on the system behavior has been explained and illustrated in chapter 4 . 


\section{Chapter 3}

\section{Hardware In the Loop}

\section{Implementation}

HIL implementation of the WEC system was done using a Typhoon HIL 604 and two baseline real-time target machines by Speedgoat. The mechanical part of the system was implemented using Speedgoat 1, controls using Speedgoat 2 and the electrical part using Typhoon HIL 604. A PC was used as a host PC to configure all the devices and to view the testing panel. Speedgoat connects to the host PC via Ethernet and the switch in the figure is the high speed NETGEAR Ethernet switch used to link

both the Speedgoat devices. The hardware rack setup used can be seen in Figure 3.1 . 


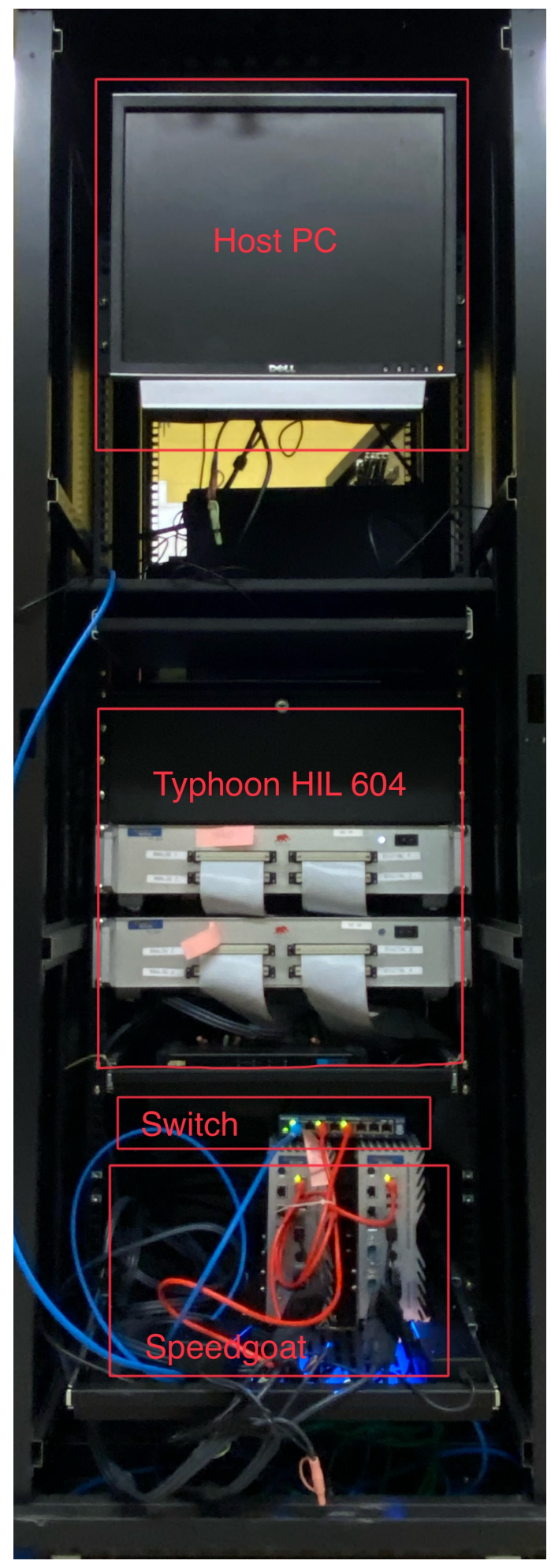

Figure 3.1: Hardware rack setup 
Figure 3.2 shows the other side of the hardware rack and the breakout boards used to get the I/O's out of the hardware can be seen.

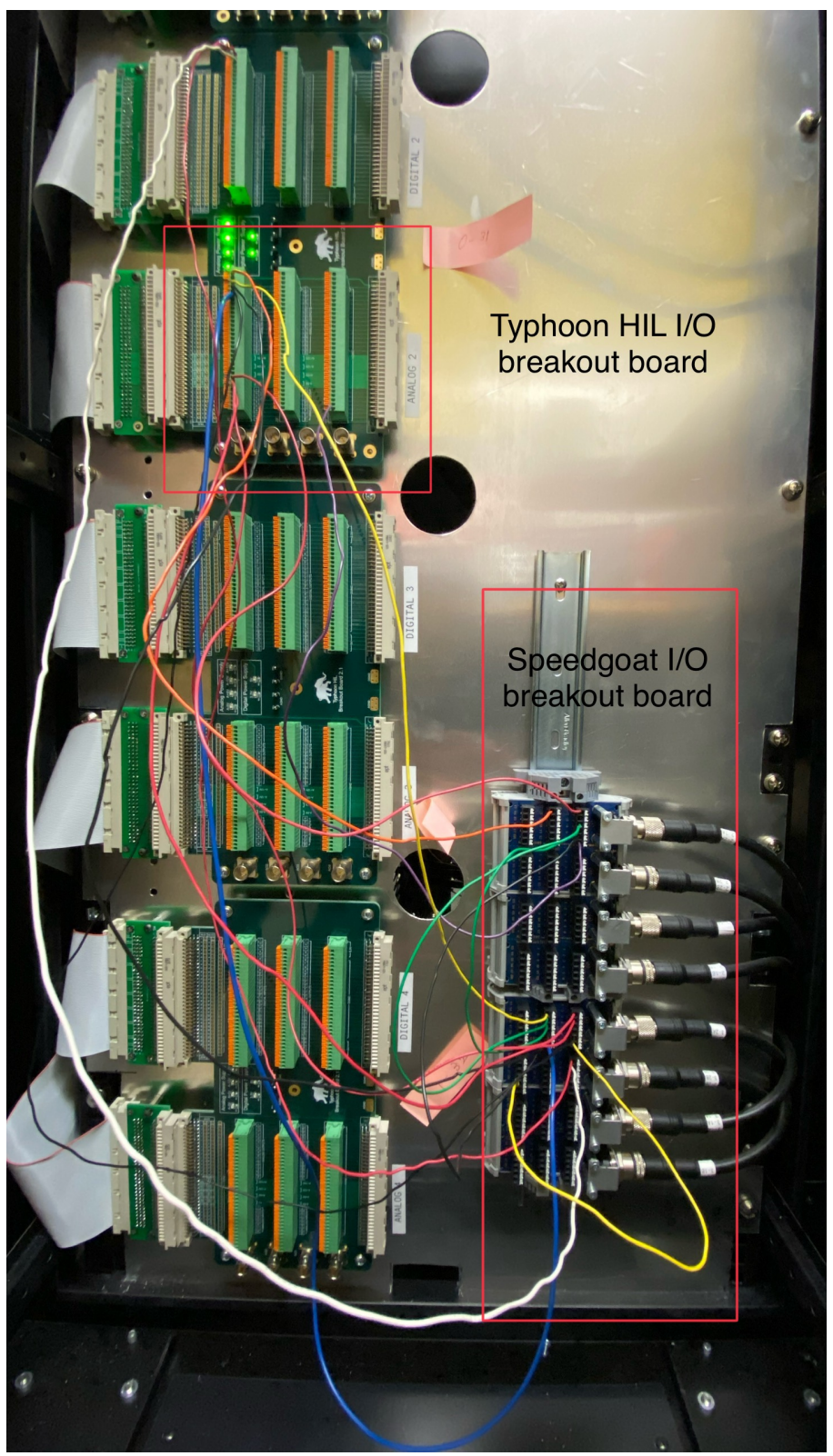

Figure 3.2: Hardware rack setup I/O's 
Tables 3.1, 3.2 and 3.3 shows the details about wiring the I/O's for the hardware devices. All the parameter values were calibrated and counter-calibrated to appropriate analog voltage ranges mentioned below in the hardware description.

Table 3.1

Hardware I/O wiring - Speedgoat 1 - mechanical sub-system

\begin{tabular}{lll}
\hline I/O & \multicolumn{1}{c}{ Parameter } & \multicolumn{1}{c}{ From/To } \\
\hline I & Machine Torque $\left(\mathrm{T}_{e}\right)$ & From Typhoon HIL 604 \\
O & Load Speed $\left(\omega_{m}\right)$ & To Typhoon HIL 604 \\
O & Position of the buoy $(\mathrm{x})$ & To Speedgoat 2 \\
O & Velocity of the buoy $(\mathrm{v})$ & To Speedgoat 2 \\
\hline
\end{tabular}

Table 3.2

Hardware I/O wiring - Speedgoat 2 - controls sub-system

\begin{tabular}{lll}
\hline I/O & \multicolumn{1}{c}{ Parameter } & \multicolumn{1}{c}{ From/To } \\
\hline I & Machine Torque $\left(\mathrm{T}_{e}\right)$ & From Typhoon HIL 604 \\
I & WEC drive current $\left(\mathrm{i}_{p t o}\right)$ & From Typhoon HIL 604 \\
I & Position of the buoy $(\mathrm{x})$ & From Speedgoat 1 \\
I & Velocity of the buoy $(\mathrm{v})$ & From Speedgoat 1 \\
O & Modulation Signal & To Typhoon HIL 604 \\
O & $\mathrm{i}_{g, r e f}$ & To Typhoon HIL 604 \\
\hline
\end{tabular}

Table 3.3

Hardware I/O wiring - Typhoon HIL 604 - electrical sub-system

\begin{tabular}{lll}
\hline I/O & \multicolumn{1}{c}{ Parameter } & \multicolumn{1}{c}{ From/To } \\
\hline I & Modulation Signal & From Speedgoat 2 \\
I & $\mathrm{i}_{g, r e f}$ & From Speedgoat 2 \\
I & Load Speed $\left(\omega_{m}\right)$ & From Speedgoat 1 \\
$\mathrm{O}$ & Machine Torque $\left(\mathrm{T}_{e}\right)$ & To Speedgoat 1 and 2 \\
$\mathrm{O}$ & WEC drive current $\left(\mathrm{i}_{\text {pto }}\right)$ & To Speedgoat 2 \\
\hline
\end{tabular}


Figure 3.3 shows the schematic of I/O's between the WEC subsystems.

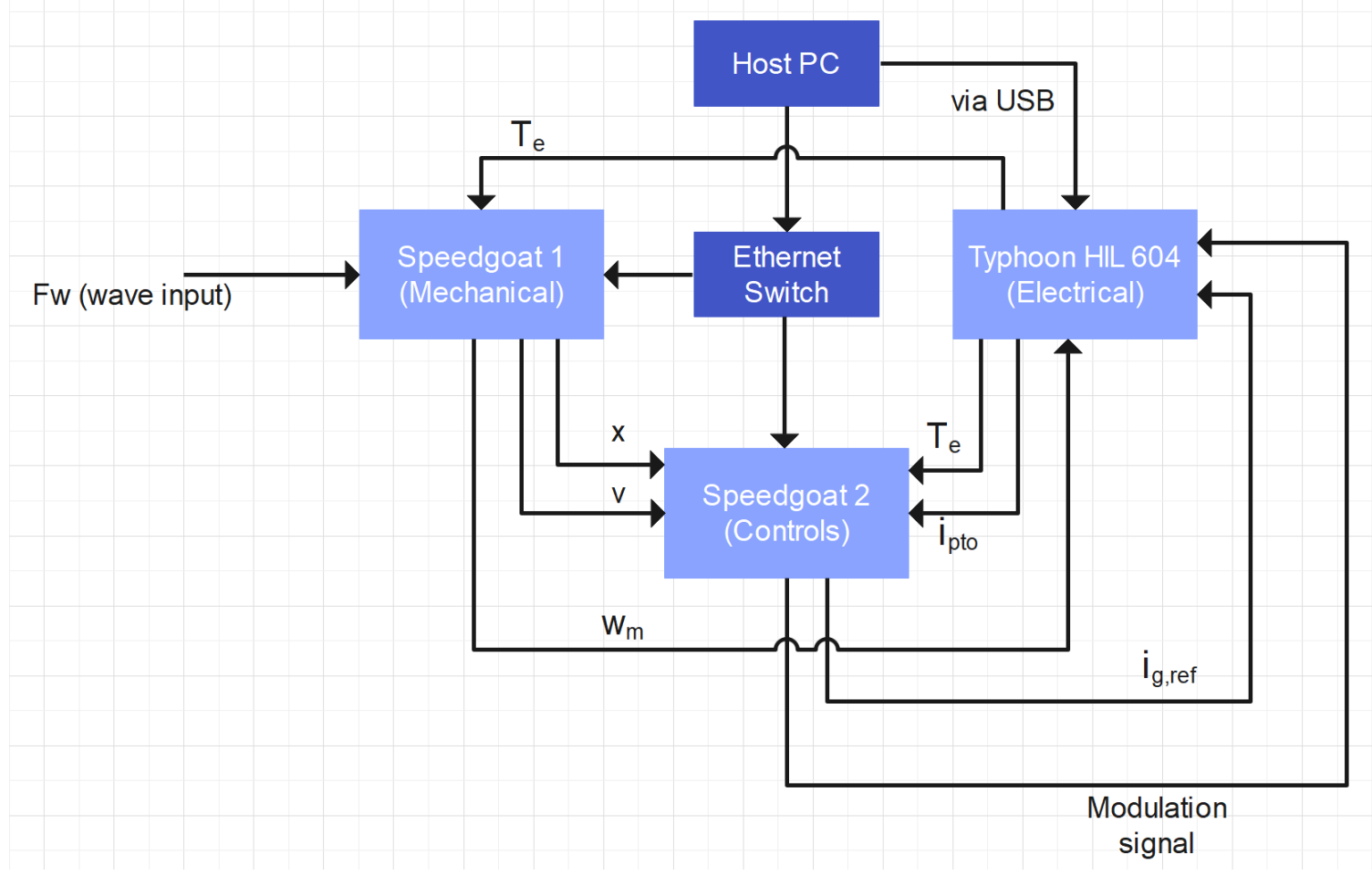

Figure 3.3: I/O wiring schematic

\subsection{Typhoon HIL}

\subsubsection{Hardware and Setup}

Typhoon HIL focuses on the products and tools for power electronics testing and validation. The hardware used for this study is the Typhoon HIL 604 [9]. HIL breakout board is used in the setup to access the analog and digital I/O [9]. Analog 
$\mathrm{I} / \mathrm{O}$ was majorly used for this study. Analog I/O has a voltage range of $\pm 10 \mathrm{~V}$. All the inputs quantities were counter-calibrated, and output quantities were calibrated such that the I/O electrical signals would stay within their limits.

Setting up a Typhoon HIL 604 is a relatively simple process. The hardware can be directly plugged into the host PC through a USB port. The PC detects the hardware, and the driver software is automatically installed [9].

\subsubsection{Modeling Tools}

Typhoon HIL Control Center is the interface used to launch Typhoon HIL tools. The tools majorly used for this study are Typhoon HIL Schematic Editor and HIL SCADA. Various other tools like the Typhoon Test IDE and Script editor can write Python-based automated tests for validating the models.

\subsubsection{Typhoon HIL Schematic Editor}

Typhoon HIL Schematic Editor is the modeling environment provided by Typhoon HIL and is one of the essential tools. It is intuitive and straightforward to use. It contains a library browser, as shown in Figure 3.4 . 


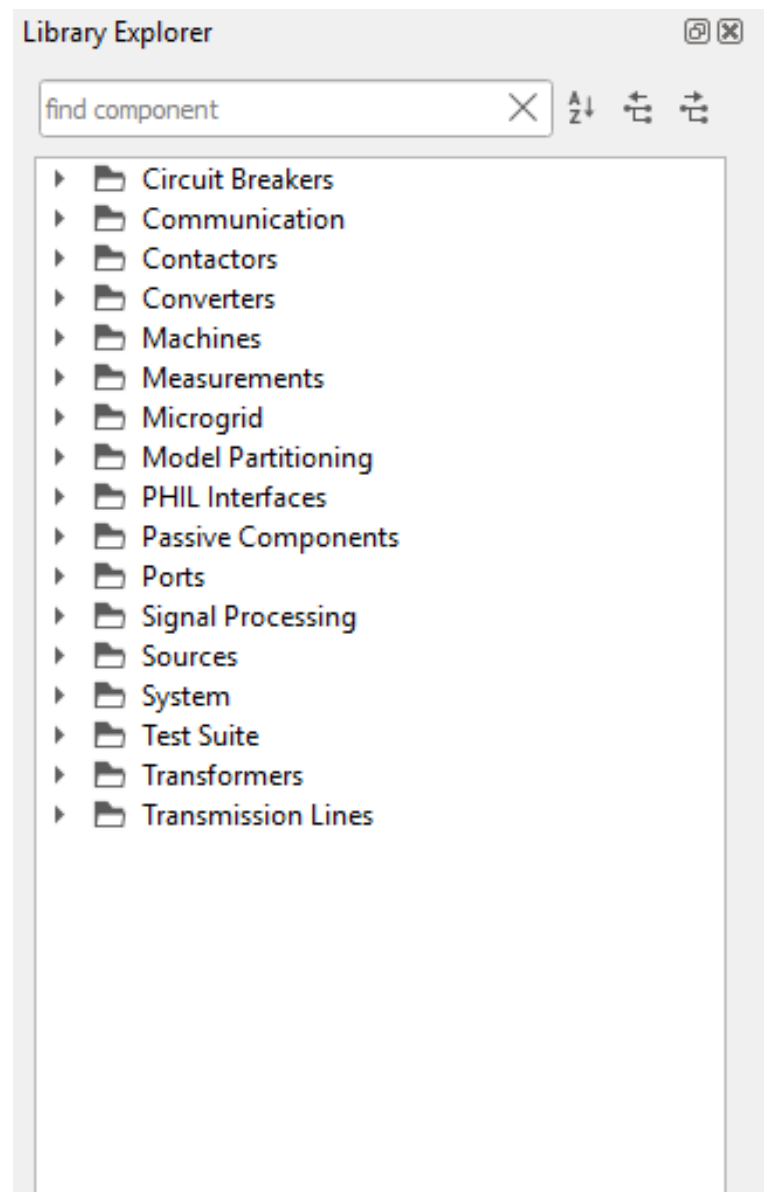

Figure 3.4: Typhoon HIL Library Browser

Any components required can be easily chosen, dragged, and dropped into the schematic. The right-most icon in the toolbar below the menu bar is a 'Compile and load in HIL SCADA' icon. This helps to compile the model and load it into HIL SCADA, which is the testing environment provided by Typhoon HIL [9]. A sample circuit built in the Typhoon HIL Schematic Editor environment can be seen in Figure 3.5 . 


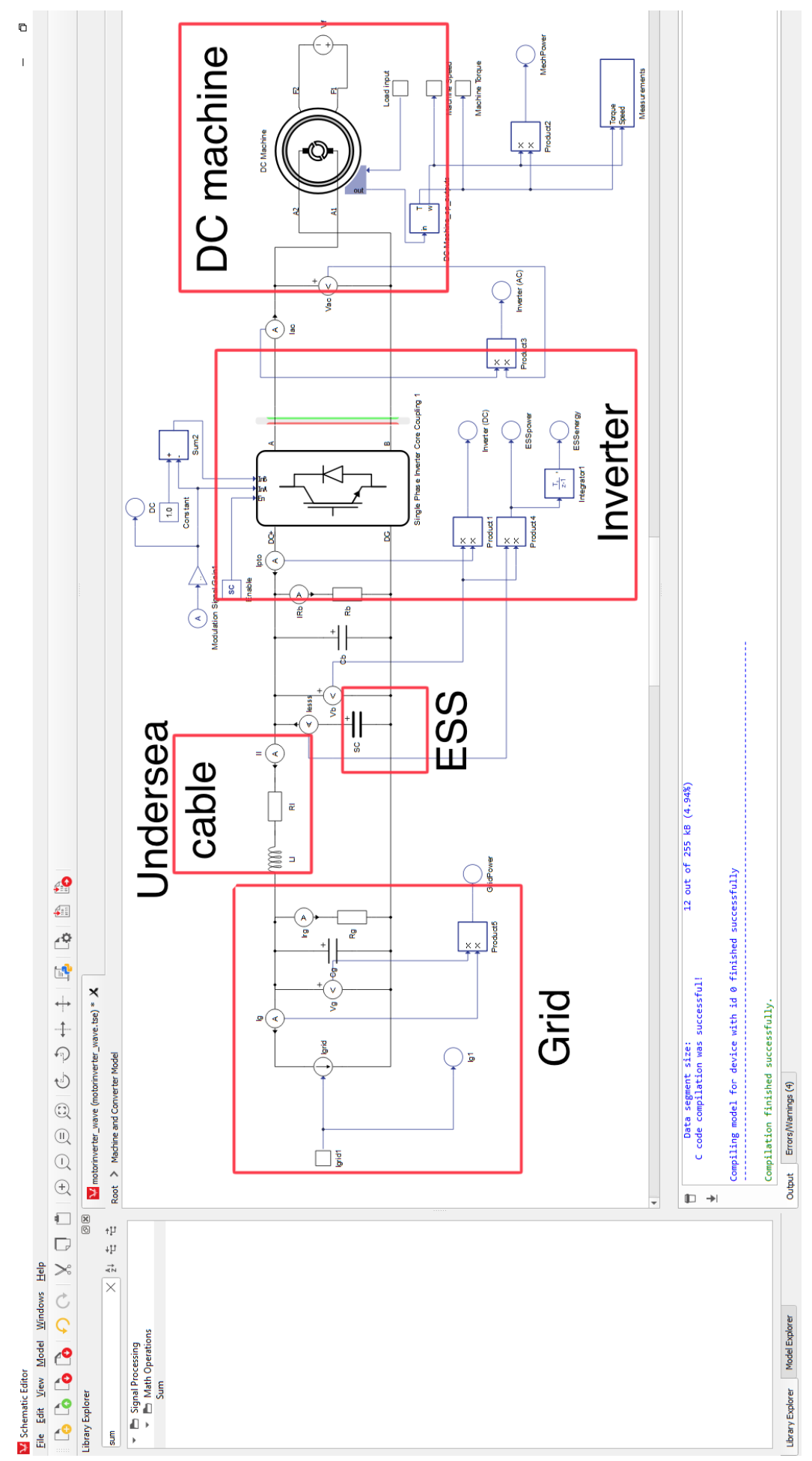

Figure 3.5: Typhoon HIL Schematic Editor environment 


\subsubsection{HIL SCADA}

HIL SCADA is the tool used to design the testing panel to validate the model. Several visual tools are available in HIL SCADA to develop the testing panel. HIL SCADA also provides an interface through 'Model Settings' to access and configure all the external/internal hardware inputs and modify the modifiable model parameters like controller gains during the data run. After the compilation process, HIL SCADA also provides an option to test the model using 'Virtual HIL (VHIL)' if the hardware device is unavailable. Figure 3.6 shows the visual tools available and the testing panel used in this study. 


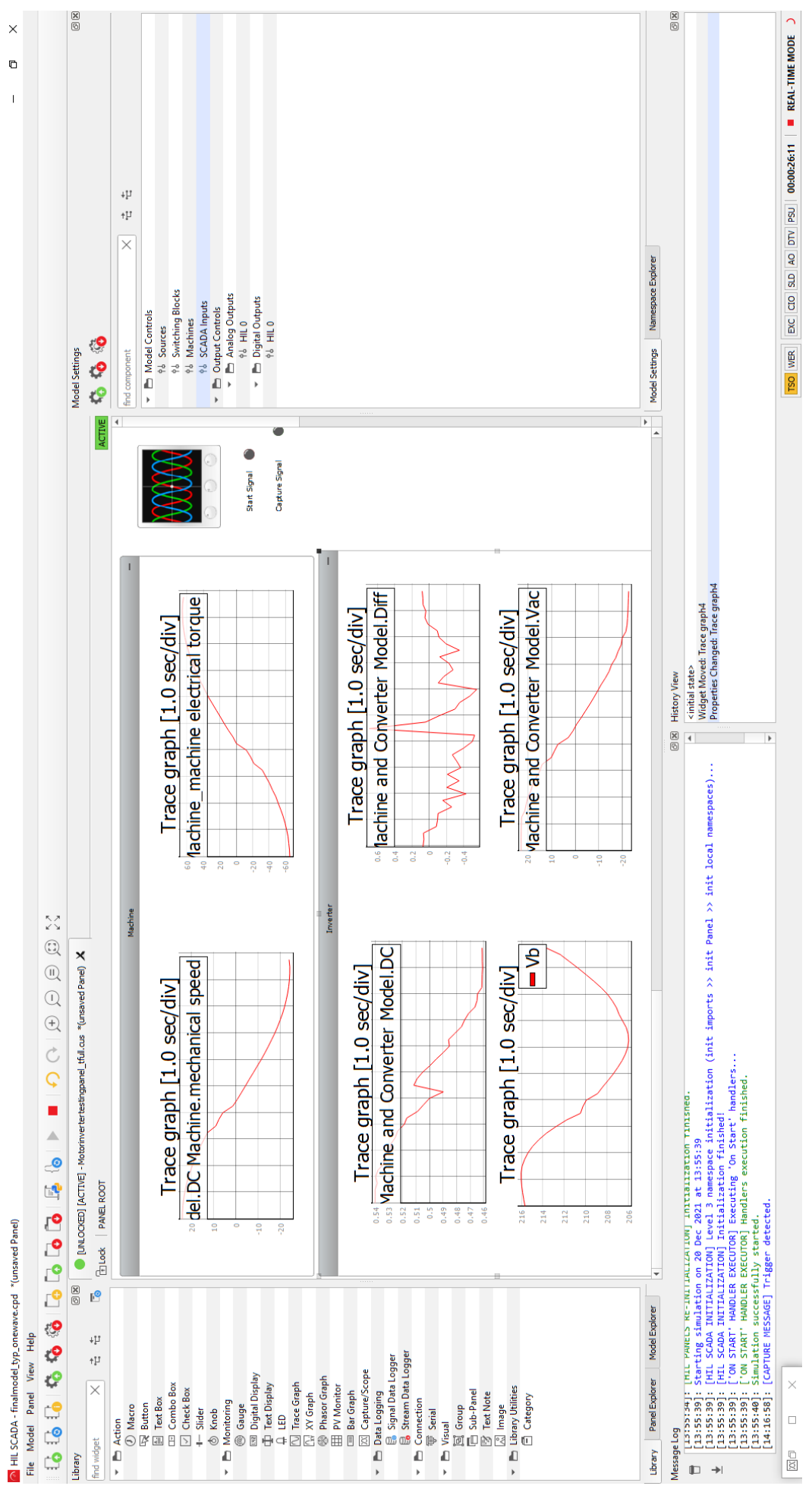

Figure 3.6: HIL SCADA testing panel 


\subsection{Speedgoat}

The Speedgoat focuses on the solutions for HIL testing and validation. Speedgoat devices are designed to be used with Simulink and Simulink Real-time from Mathworks. As Simulink has an extensive library, Speedgoat can be used for a wide range of applications compared to Typhoon HIL.

\subsubsection{Hardware and Setup}

Two 'Baseline Real-Time Target Machines' were used during this study. One of the advantages of Speedgoat target machines is that they have I/O boards and specifications that can be assembled according to the purpose of the customer. Each target machine used in this study has two I/O boards assembled, namely IO183 and IO397. Analog I/O ports of the IO183 module were used during this study. The module has eight analog inputs with a voltage range of $\pm 10 \mathrm{~V}$ and four analog outputs that can be configured as either $0-2.5 \mathrm{~V}$ or $0-5 \mathrm{~V}$. All the inputs quantities were counter-calibrated, and output quantities were calibrated such that the I/O electrical signals would stay within their limits.

Speedgoat setup is comparatively complicated as compared to Typhoon HIL. 
The host PC should have MATLAB, Simulink, MATLAB and Simulink Coders, and Simulink Real-Time installed. Using Speedgoat involves building the model and code generation; hence, a required C-compiler version should be installed. The Speedgoat libraries for Simulink Real-Time should be installed. The models used for this study can be seen in Figure 3.7. The target machine should be powered. The Ethernet cable

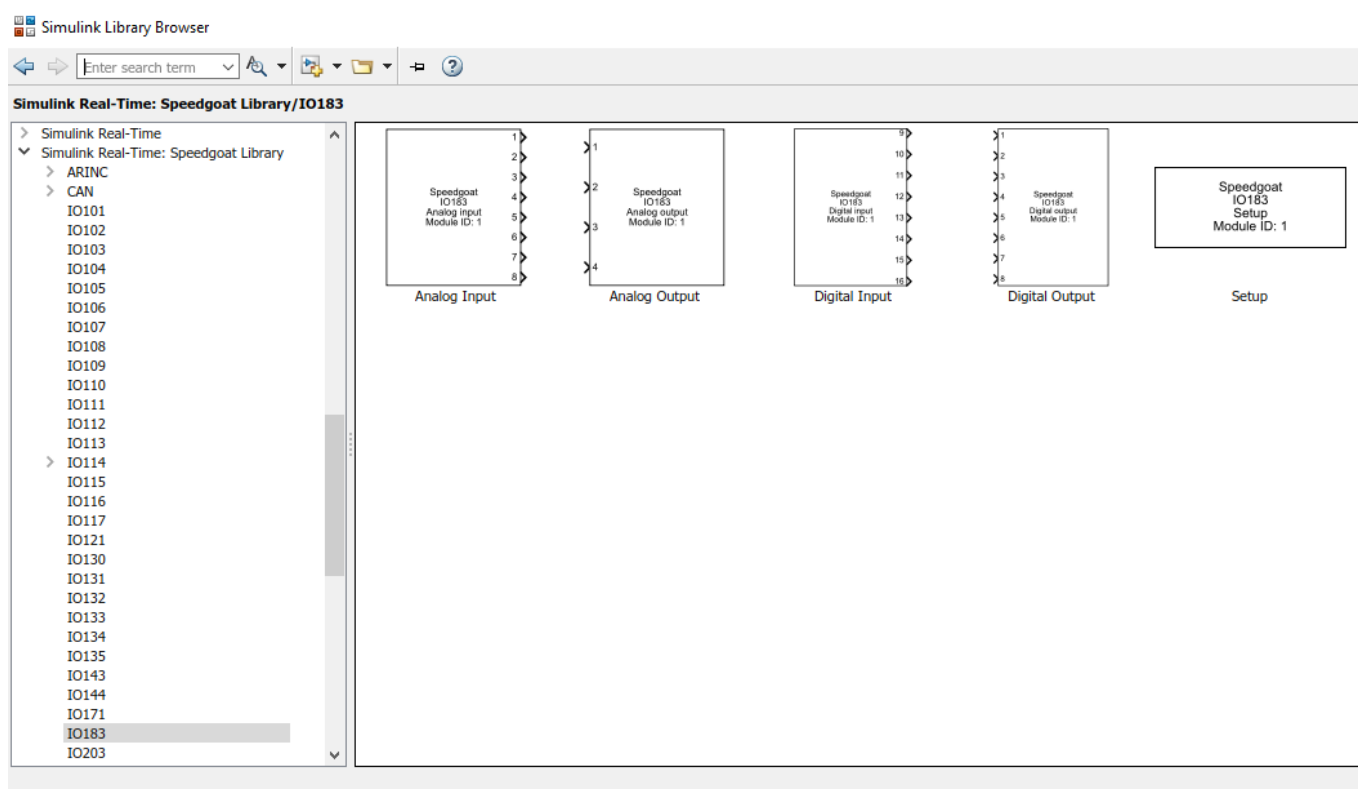

Figure 3.7: IO183 models from Simulink Real-Time library

should connect the target machine and the host PC. In this study, a NETGEAR highspeed ethernet switch has been used to establish the common connection between the Speedgoat devices. On the host PC, through the 'Network and Sharing Center,' the 'Internet Protocol Version 4' properties should be configured for Ethernet.On MATLAB, the target machines can be accessed using the 'slrtexplr' command. Then, the connection can be established by changing the 'Host to Target Communication' properties to the preconfigured target machine TCP/IP settings. The target can be 
pinged using the 'ping' command to test the communication between the target and the host PC.

\subsubsection{Modeling Tools}

MATLAB was used to initialize the parameters for the Simulink models. It was also used to process and analyze the data captured through Typhoon HIL. Simulink was used to develop, compile and build the models. Simulink requires a few setup procedures before running real-time models, and they are setting the simulation mode to 'External' as shown in Figure 3.8. The right most icon is used to build the model.

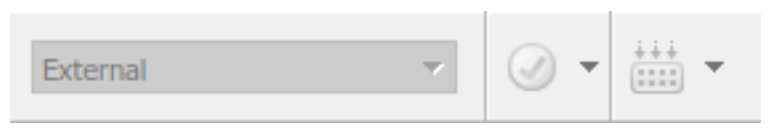

Figure 3.8: Simulation mode setup

Under the model configuration parameters, code generation settings and Simulink Real-Time options need to be setup. The target machine to build the model can be specified through these settings. Figures 3.9 and 3.10 shows the setup. 


\section{Q Search}

\begin{tabular}{|l|}
\hline Solver \\
Data Import/Export \\
Math and Data Types \\
- Diagnostics \\
Hardware Implementation \\
Model Referencing \\
Simulation Target \\
- Code Generation \\
Optimization \\
Report \\
Comments \\
Symbols \\
Custom Code \\
Verification \\
Simulink Real-Time Options \\
Coverage \\
HDL Code Generation \\
Simscape \\
Simscape Multibody 1G \\
Simscape Multibody \\
\end{tabular}

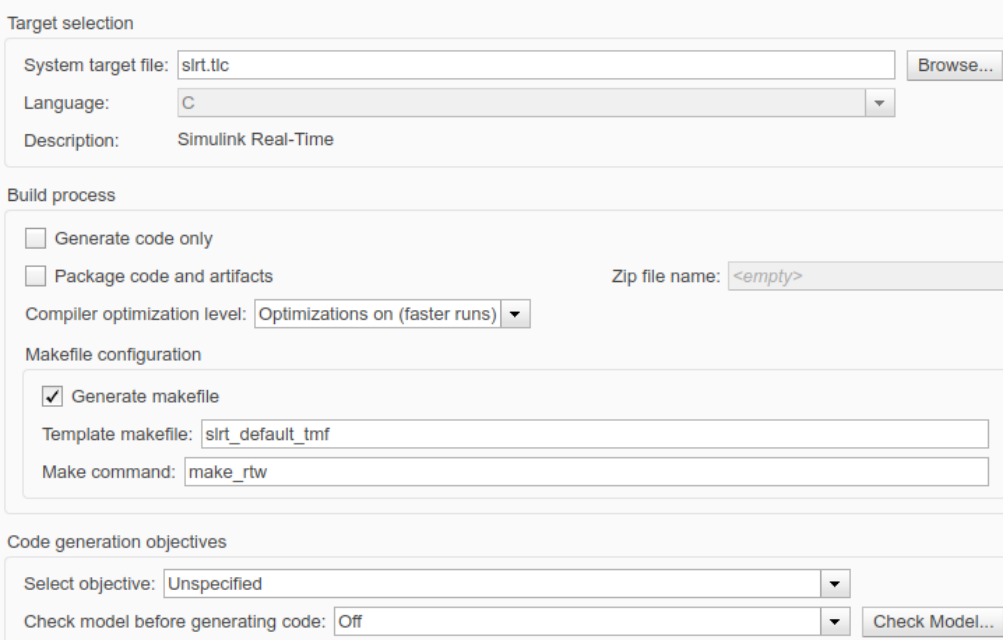

Figure 3.9: Model code generation settings

Figure 3.10: Model real-time target configuration settings 


\section{Chapter 4}

\section{Results and Discussions}

\subsection{Preliminary WEC model results}

\subsubsection{Single frequency wave test}

The results presented in this section show the plots for all the essential WEC parameters for an update rate $\tau_{f f}=1 \mathrm{~s}$. The wave force is the only input to the model, and for the presented case, wave force $\left(\mathrm{F}_{w}\right)$ is $5000 \mathrm{~N}$ and the wave period is $20 \mathrm{~s}$.

Figure 4.1 shows the linear forces on the buoy. $F_{w}$ is the wave input provided to the system, and $\mathrm{F}_{\mathrm{e}}$ is the actuator force. The actuator force is a reaction force to the 
wave input; hence, it is out of phase with the wave force.

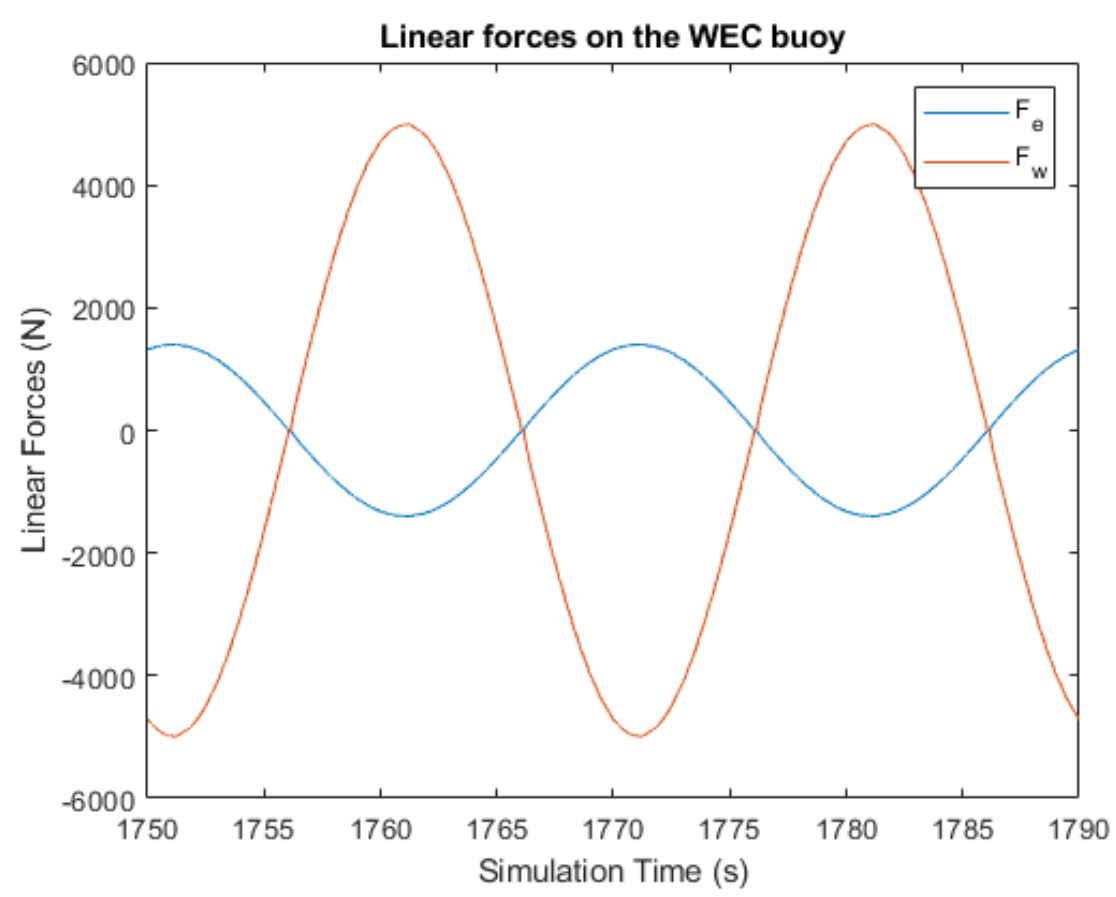

Figure 4.1: Linear forces on the buoy - single frequency

Figures 4.2 and 4.3 show the vertical position and velocity of the buoy. From the reference, the buoy exhibits a vertical movement between 4 and $-4 \mathrm{~m}$. At the highest and lowest position, the velocity of the buoy becomes zero. The maximum velocity of the buoy was observed to be $1.15 \mathrm{~m} / \mathrm{s}$. 


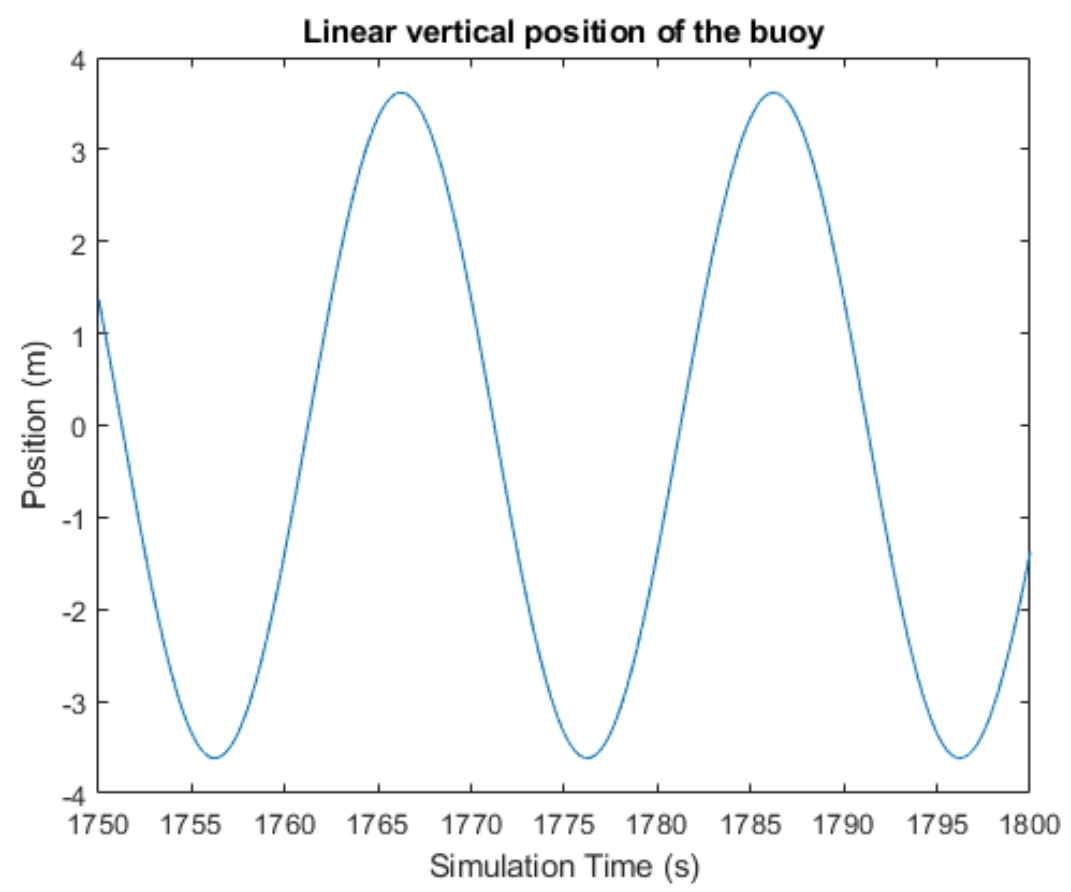

Figure 4.2: Linear vertical position of the buoy - single frequency

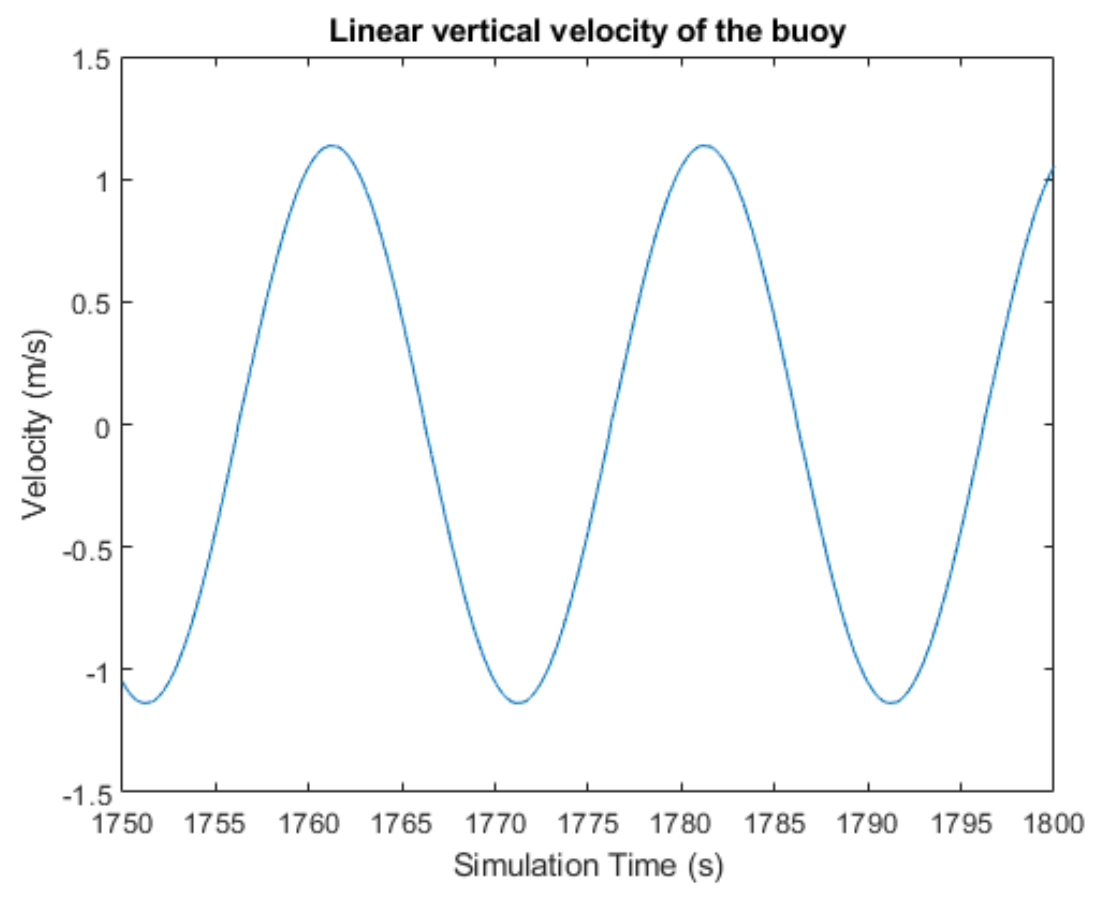

Figure 4.3: Linear vertical velocity of the buoy - single frequency 
The speed of the machine is shown in Figure 4.4. It can be validated using

$$
\omega_{m}=\frac{\text { Vertical velocity of the buoy }}{\text { Gear radius }}=\frac{1.15}{0.047}=24.46 \mathrm{rad} / \mathrm{s} .
$$

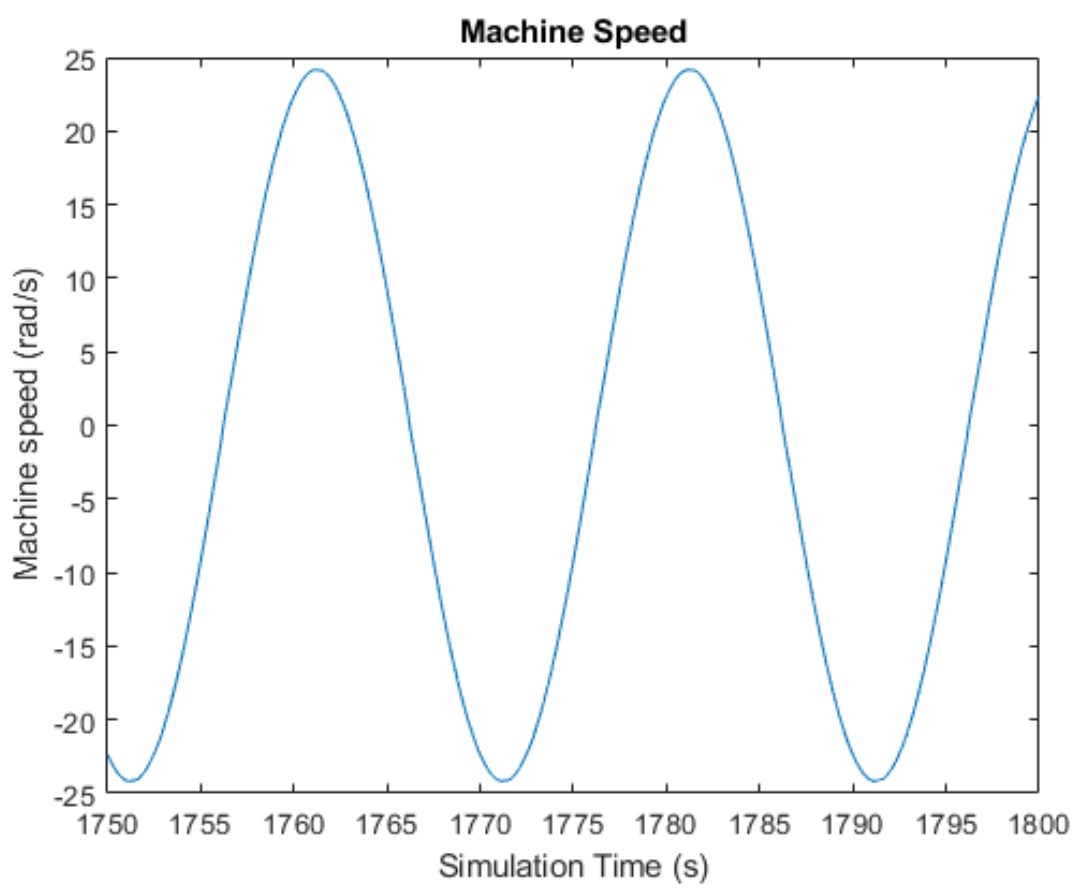

Figure 4.4: Speed of the DC machine - single frequency

The torque of the machine is generated through inverter PI control scheme (section 2.3.2). The reference torque generated through the reference actuator force $\left(\mathrm{F}_{\mathrm{e}, \mathrm{ref}}\right)$ as mentioned in section 2.3.1 can be seen in Figure 4.5. It can also be observed that the PI controller (section 2.3.2 does not have an error because the machine is achieving the reference torque. 


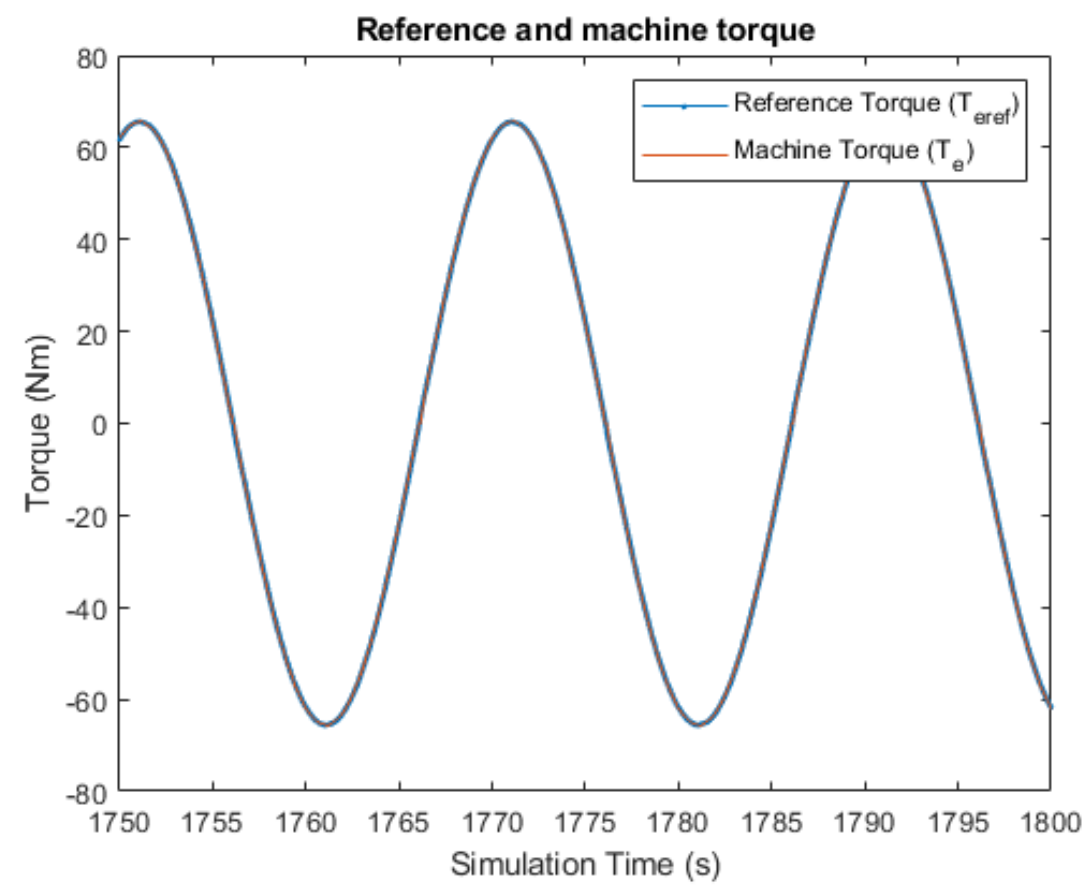

Figure 4.5: DC machine reference and actual torque - single frequency 
Figure 4.6 shows the modulation signal generated by the PI controller (section 2.3.2) for the inverter control. It has an impact on the current from the WEC drive and the bus voltage.

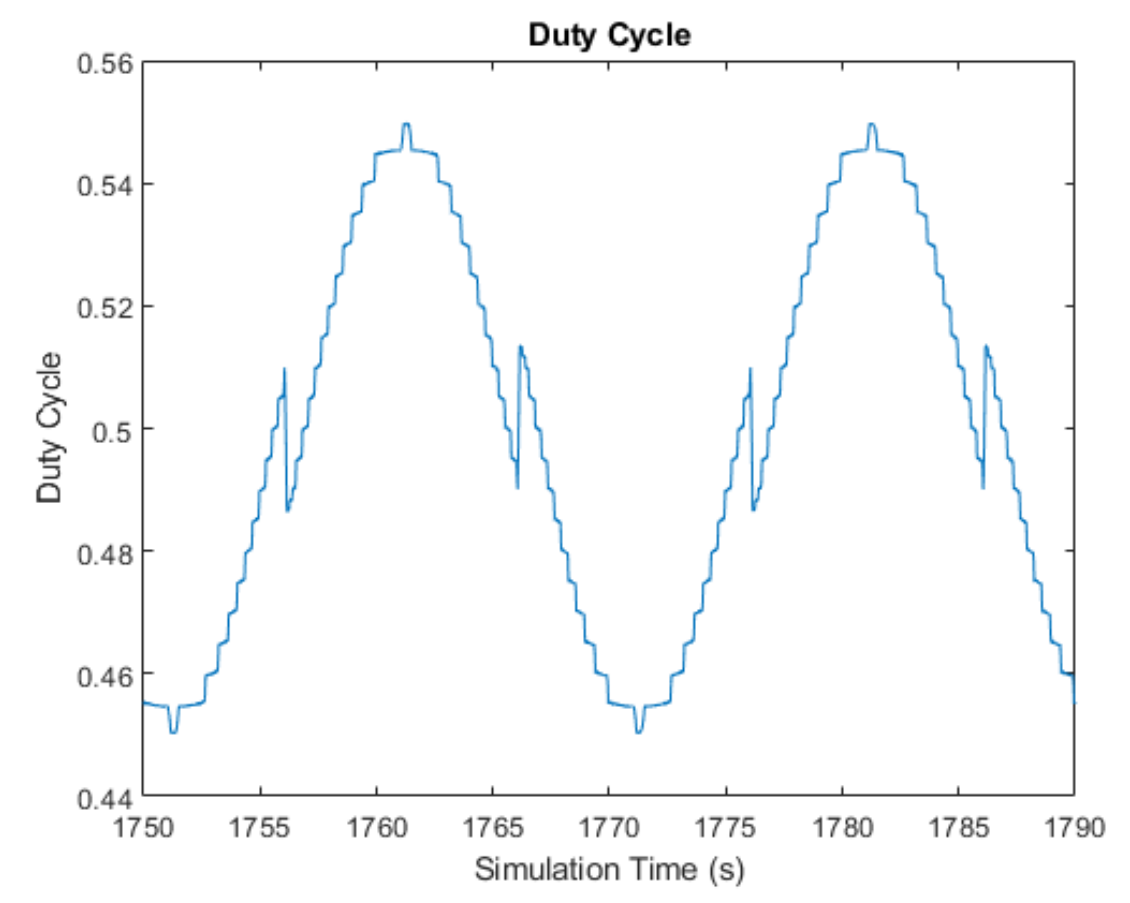

Figure 4.6: Modulation signal for inverter control - single frequency

The variation in the modulation signal is due to the variation in motor torque at zero. The torque transience is shown in Figure 4.7. But, as the variation stays for a time factor lower than $0.2 \mathrm{~s}$ and the controller catches up with the signal, the effect can be ignored. 


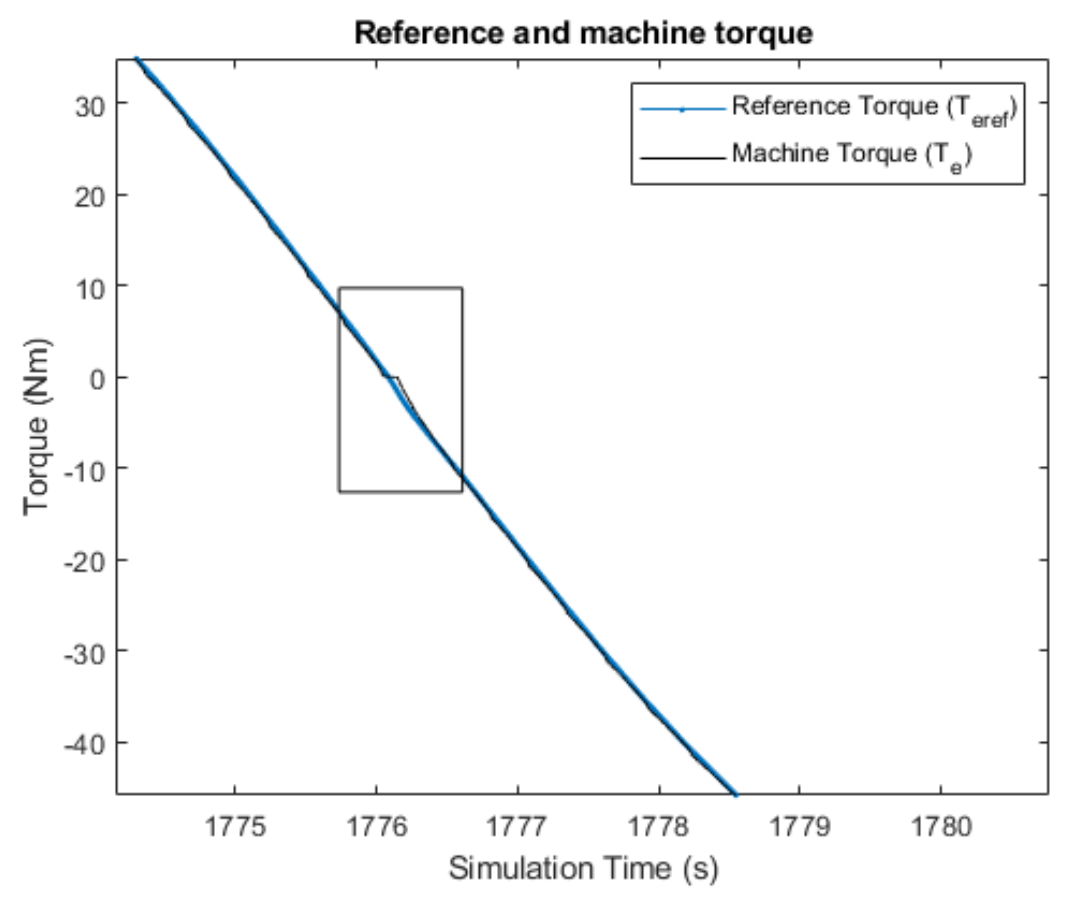

Figure 4.7: Torque variation

The current from the WEC drive is a significant parameter. The current from the WEC drive $\mathrm{i}_{\text {pto }}$ is shown in Figure 4.8 and it peaks at around $8 \mathrm{~A}$ for this case. The $\mathrm{i}_{\text {pto }}$ is always positive justifying that power extraction from the input wave is happening. It can be observed that the impact of the variation in the modulation signal at the positive and negative peaks is reflected in the current from the WEC drive. The same effect is seen in the bus voltage as well in Figure 4.9. The frequency of these signals is twice the wave frequency period because of the positive and negative peaks of the input wave. The bus voltage is also achieving the reference bus voltage value at $200 \mathrm{~V}$ (section 2.3.3). 


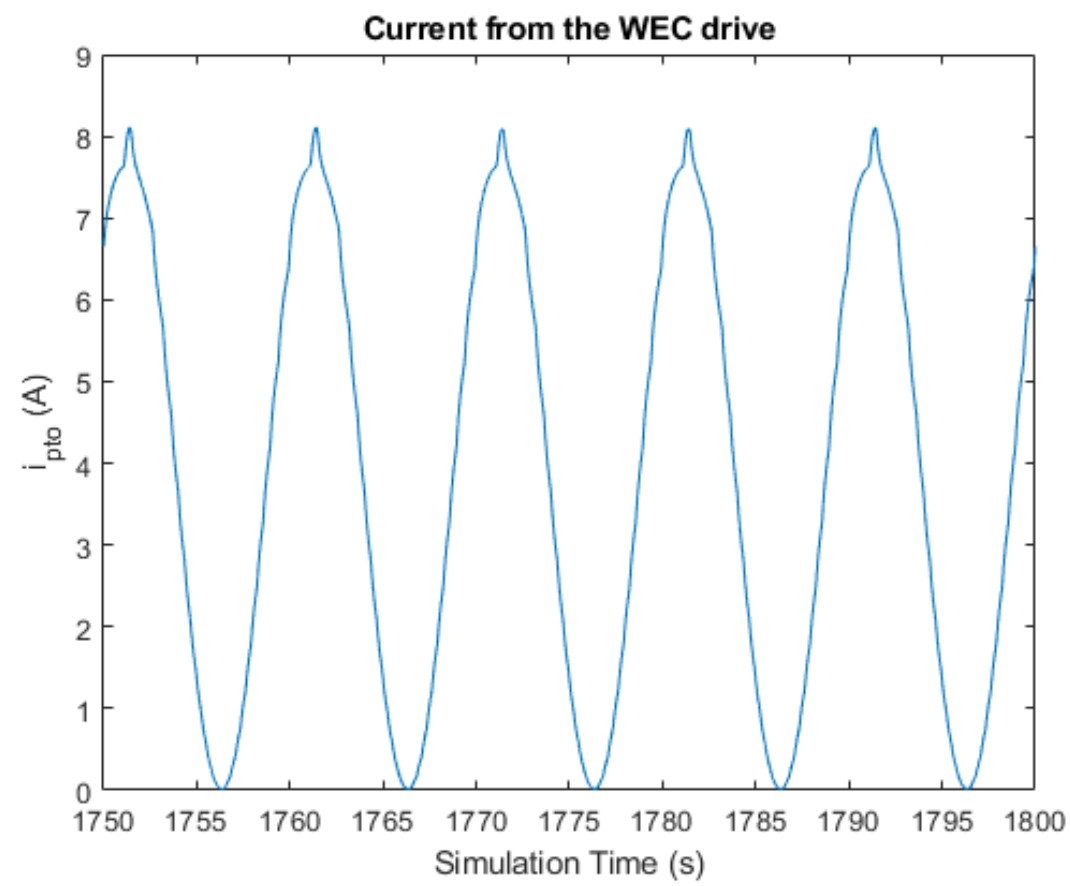

Figure 4.8: Current from the WEC drive - single frequency

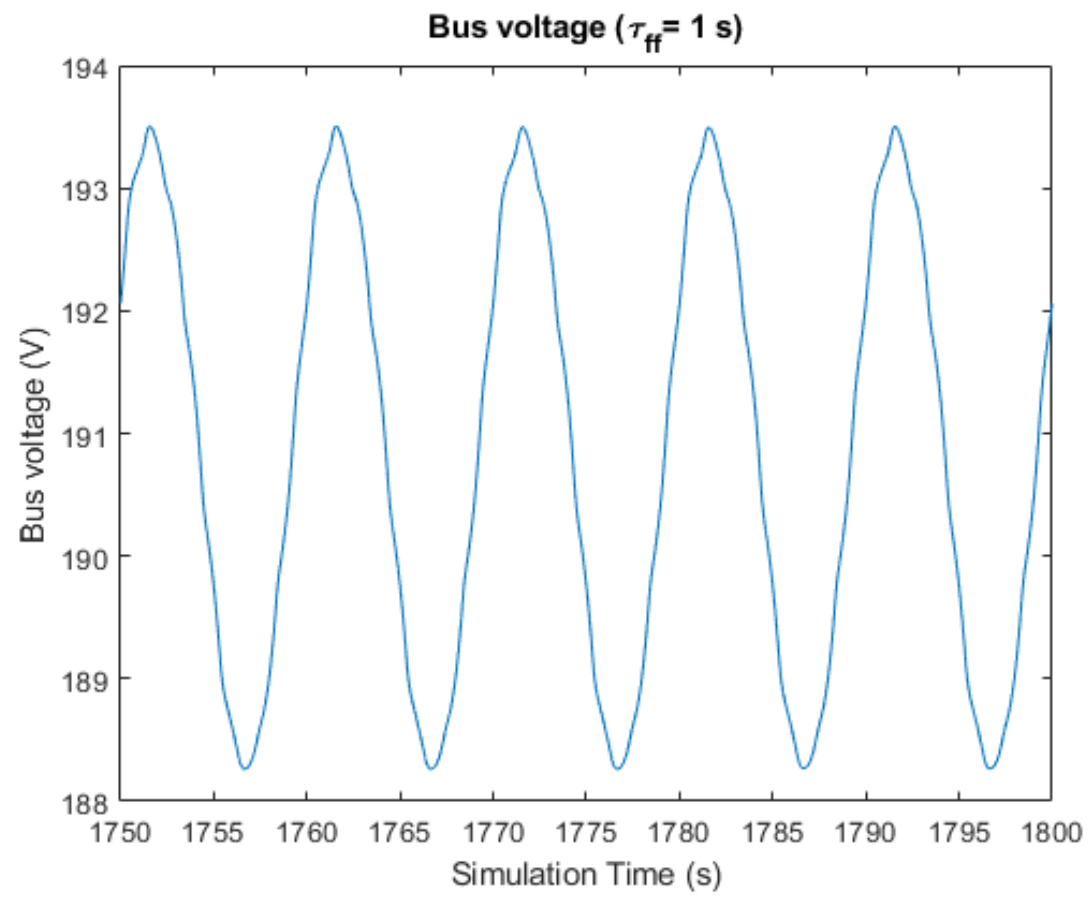

Figure 4.9: Bus voltage for $\tau_{f f}=1 \mathrm{~s}$ case - single frequency 
The power flow in the WEC system is illustrated in Figure 4.10, It can be observed that the mechanical power is the highest. As the power flows in the system from the mechanical end to the grid, several losses are happening due to the parasitic elements. The peak mechanical power generated for this case is close to $1600 \mathrm{~W}$ and it reduces to $1300 \mathrm{~W}$ at grid.

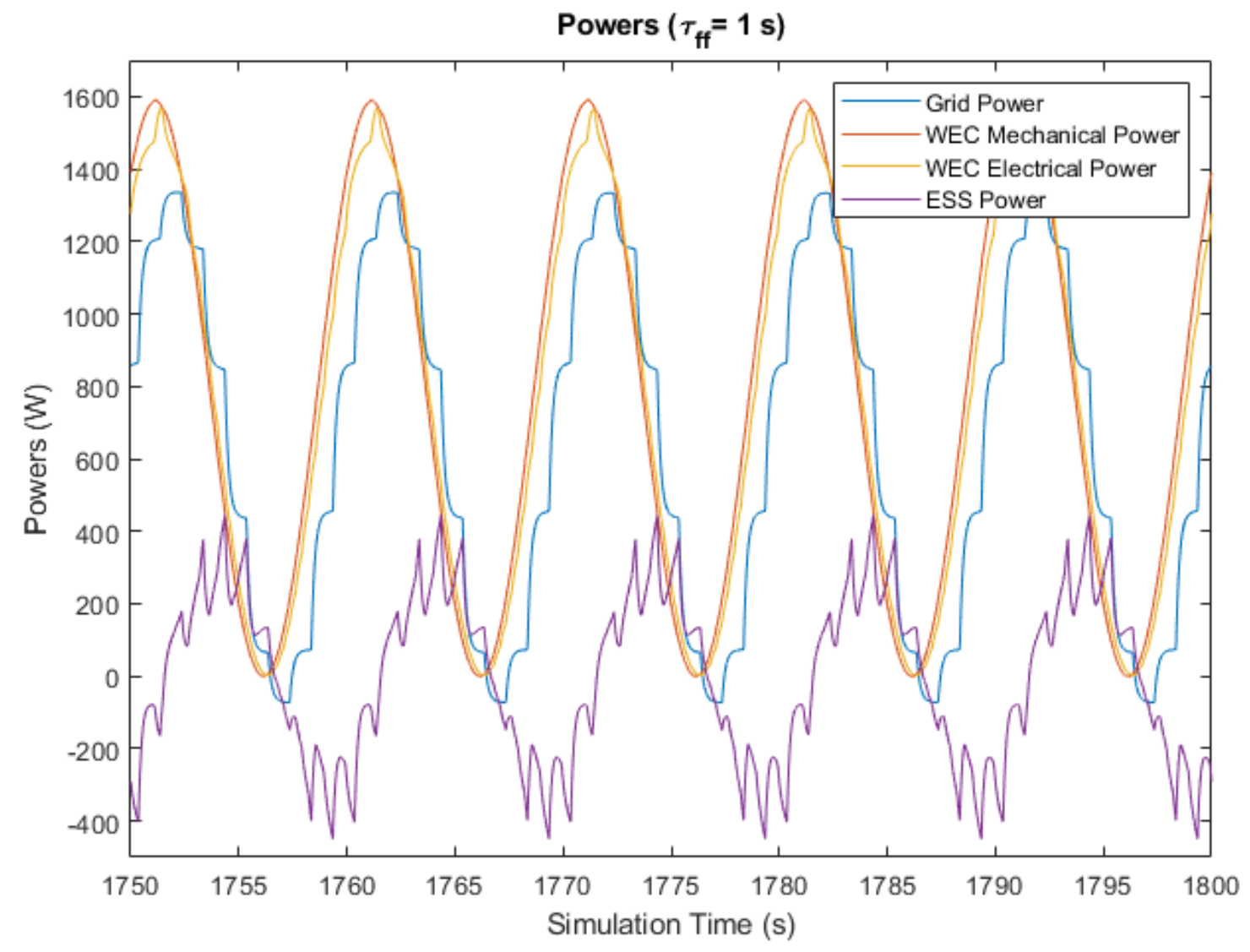

Figure 4.10: Powers in the WEC system for $\tau_{f f}=1 \mathrm{~s}$ - single frequency 
Similarly, Figure 4.11 shows the current flows in the WEC system. The reference grid current is updated as per the update rate. The WEC supplies the grid current/exporting power as per the reference current. It can also be observed that as per the grid reference current, the ESS is charging and discharging.

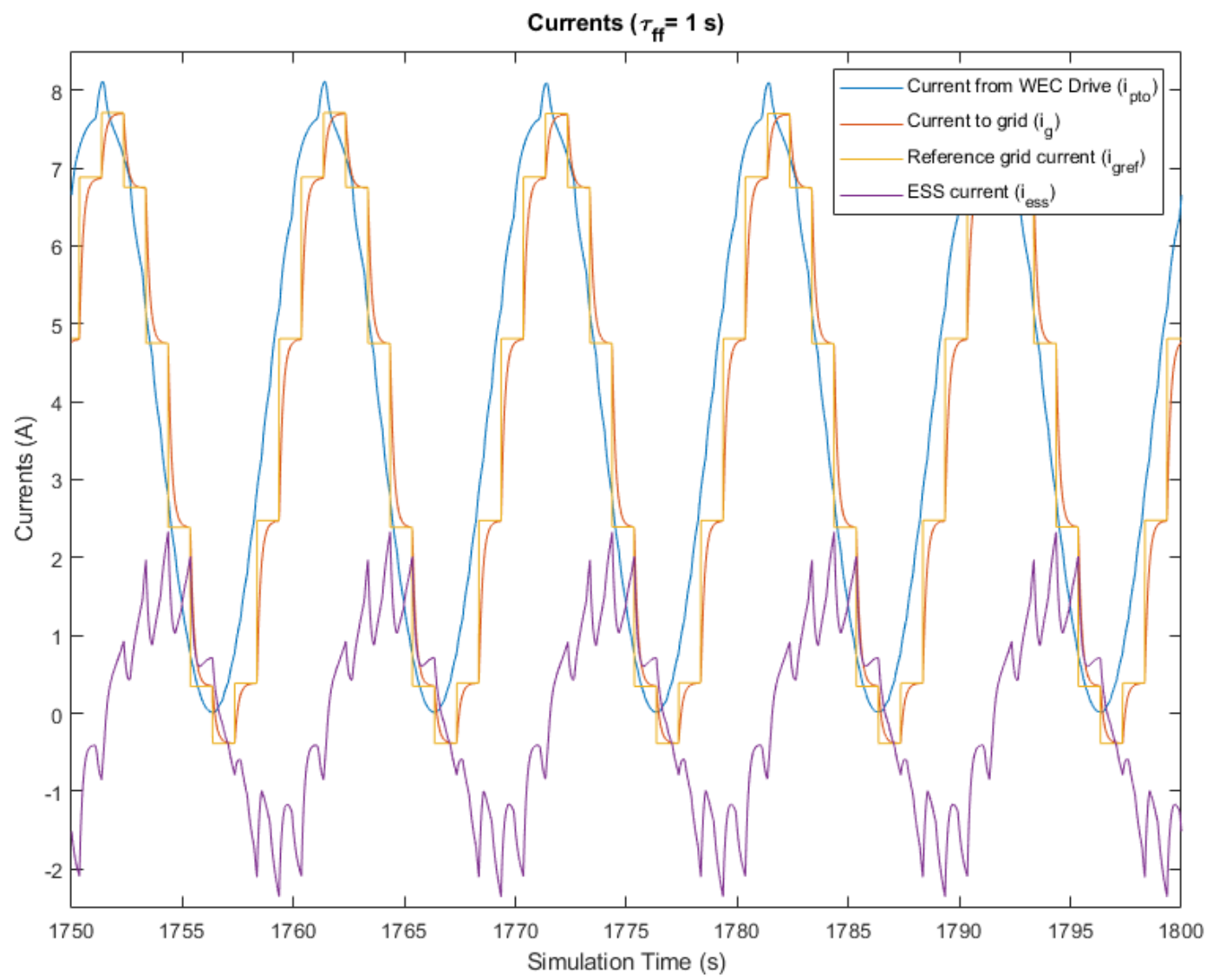

Figure 4.11: Currents in the WEC system for $\tau_{f f}=1 \mathrm{~s}$ - single frequency 
The efficiency of the system for this case can be computed as

$$
\eta=\frac{\text { Average Grid Power }}{\text { Average Mechanical Power }}=\frac{639.7760}{792.9071}=80.69 \% \text {. }
$$

\subsubsection{Multiple frequency wave test}

The results presented in this section show the plots for all the essential WEC parameters for an update rate $\tau_{f f}=1 \mathrm{~s}$. In the real-world, most of the waves encountered are multi-frequency waves. Hence, in this case, the sum of two waves with different frequencies is the input to the model. For the presented case, wave forces are $\mathrm{F}_{w 1}=5000 \mathrm{~N}$ and $\mathrm{F}_{w 2}=3000 \mathrm{~N}$. The wave periods are 20 and $5 \mathrm{~s}$ respectively.

Figure 4.12 shows the linear forces on the buoy due to multi-frequency waves. $\mathrm{F}_{\mathrm{e}}$ is the actuator force for the provided wave input. The actuator force is a reaction force to the wave input; hence, it is out of phase with the wave force. 


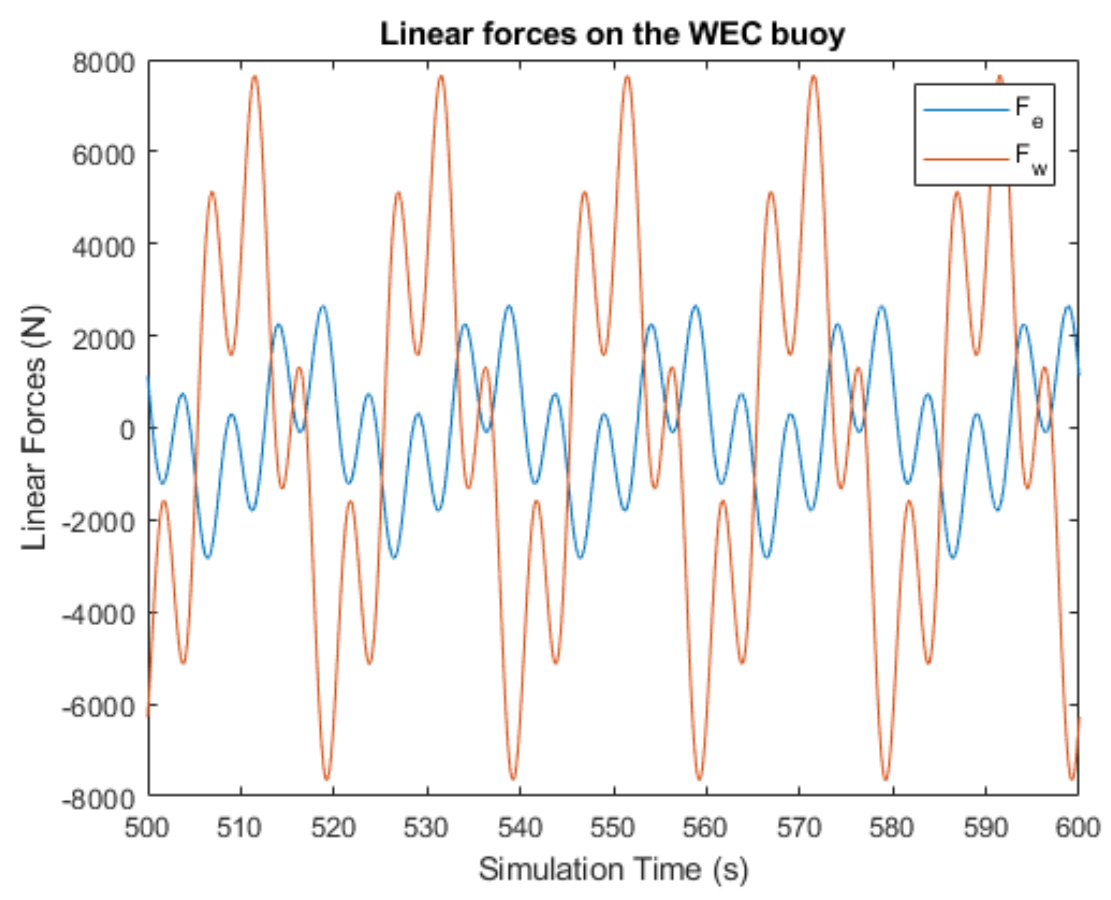

Figure 4.12: Linear forces on the buoy - multi-frequency

Figures 4.13 and 4.14 show the vertical position and velocity of the buoy respectively for multi-frequency waves. From the reference, the buoy exhibits a vertical movement between 4.5 and $-4.5 \mathrm{~m}$. At the highest and lowest position, the velocity of the buoy becomes zero. The maximum velocity of the buoy was observed to be $2.3 \mathrm{~m} / \mathrm{s}$. 


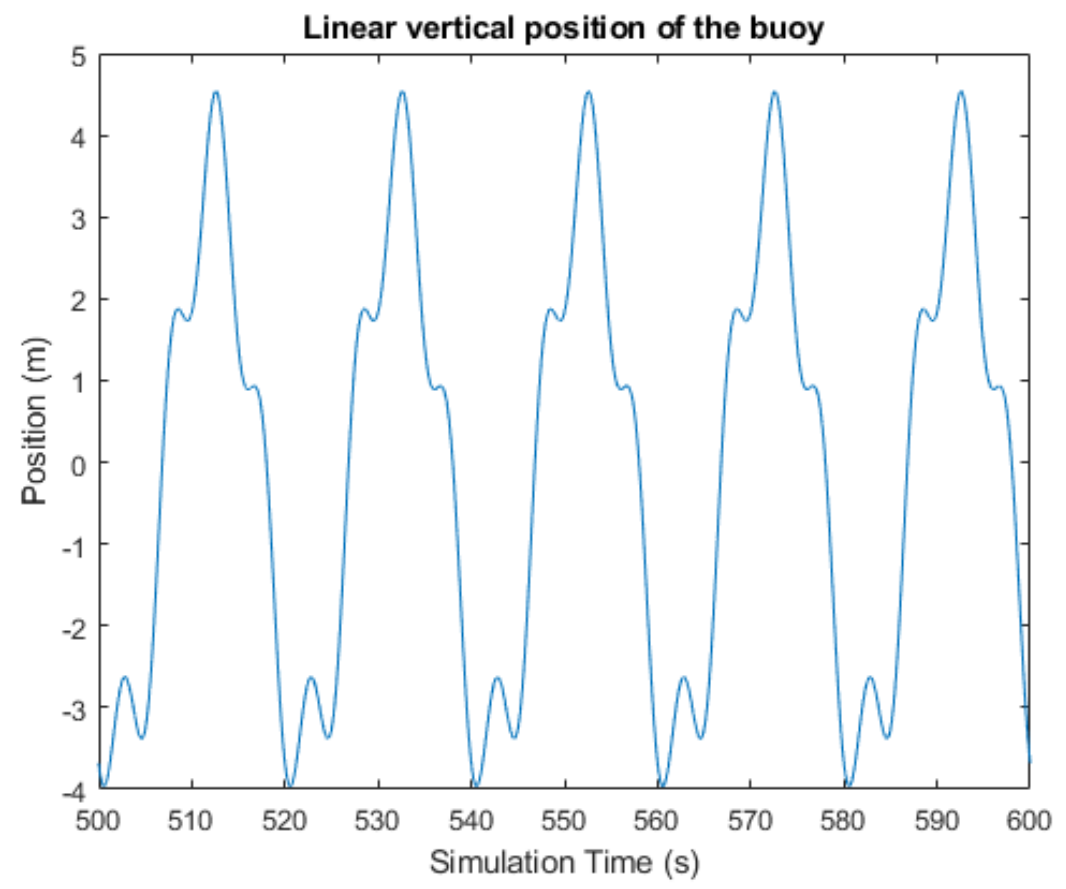

Figure 4.13: Linear vertical position of the buoy - multi-frequency

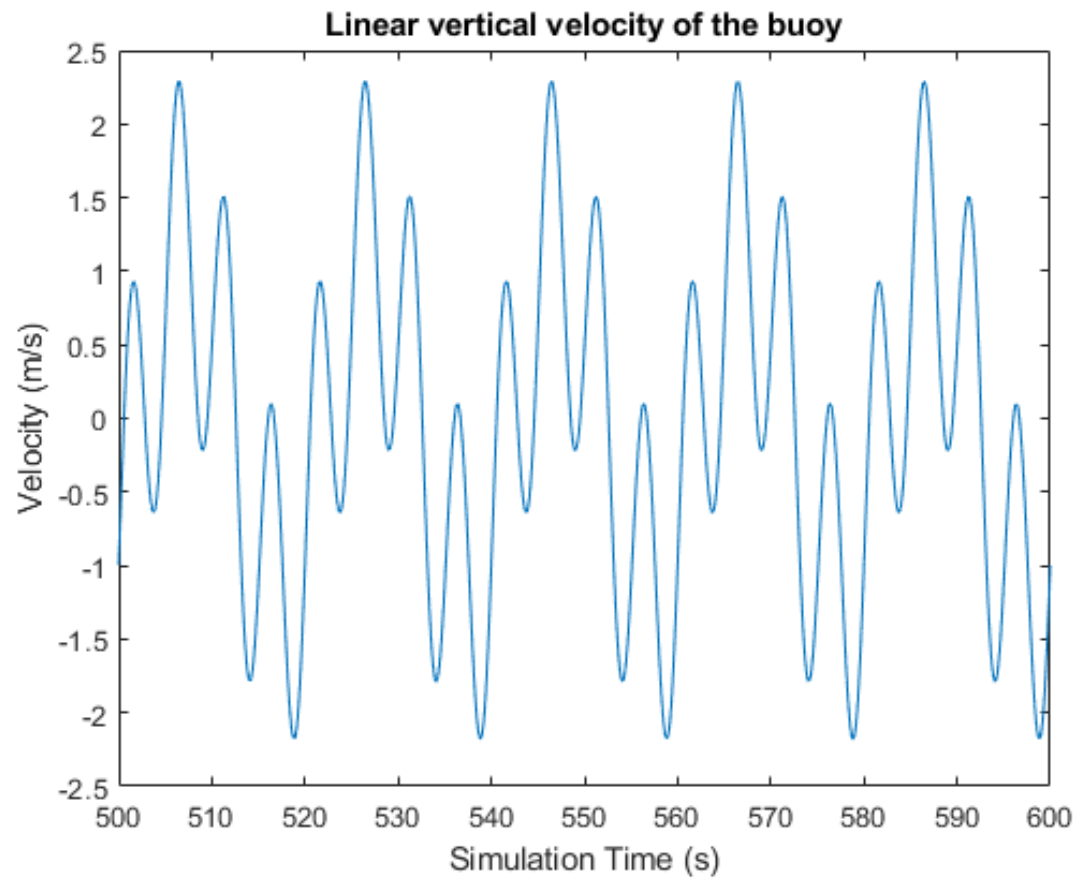

Figure 4.14: Linear vertical velocity of the buoy - multi-frequency 
The speed of the machine is shown in Figure 4.15. It can be validated using equation 2.4 to be

$$
\omega_{m}=\frac{\text { Vertical velocity of the buoy }}{\text { Gear radius }}=\frac{2.3}{0.047}=48.93 \mathrm{rad} / \mathrm{s} .
$$

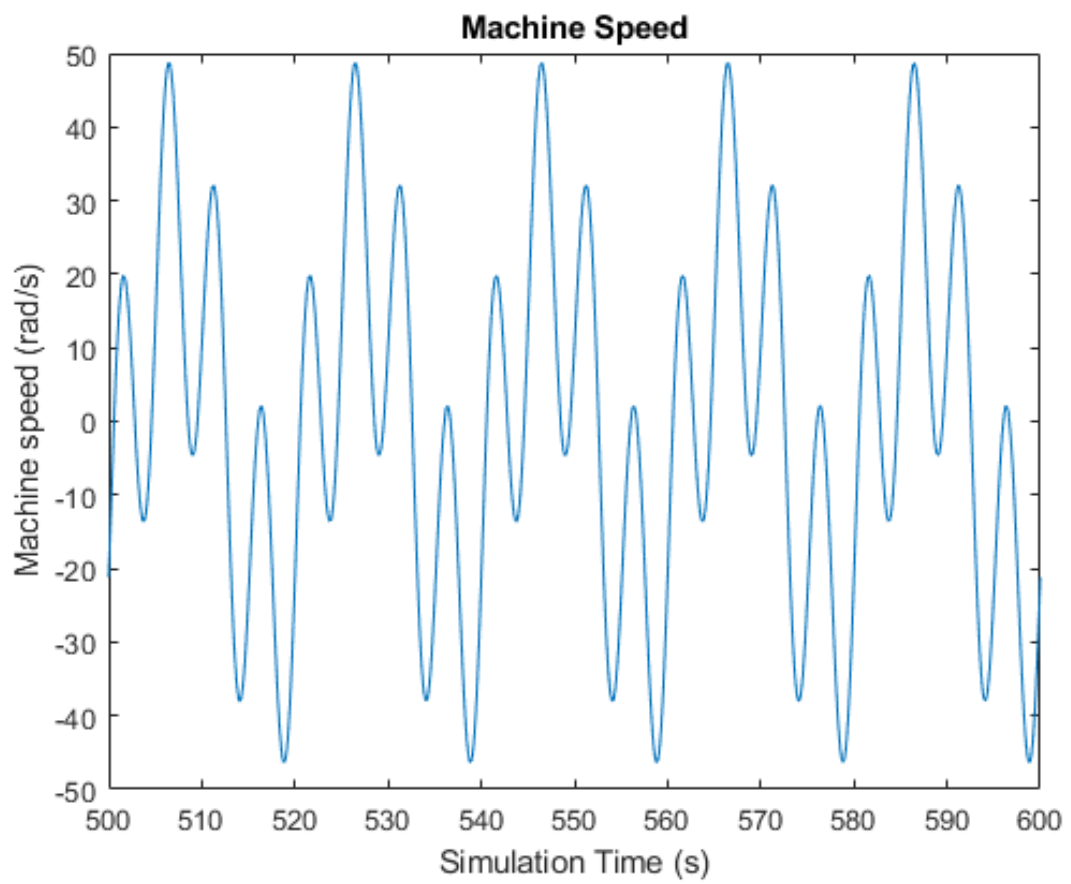

Figure 4.15: Speed of the DC machine - multi-frequency

The torque of the machine is generated through inverter PI control scheme (section 2.3.2. The reference torque generated through the reference actuator force $\left(\mathrm{F}_{\mathrm{e}, \mathrm{ref}}\right)$ as mentioned in section 2.3.1 can be seen in Figure 4.16. It can also be observed that the PI controller (section 2.3.2 does not have an error because the machine is achieving the reference torque. This validates that the system works well for both single and 
multi-frequency waves.

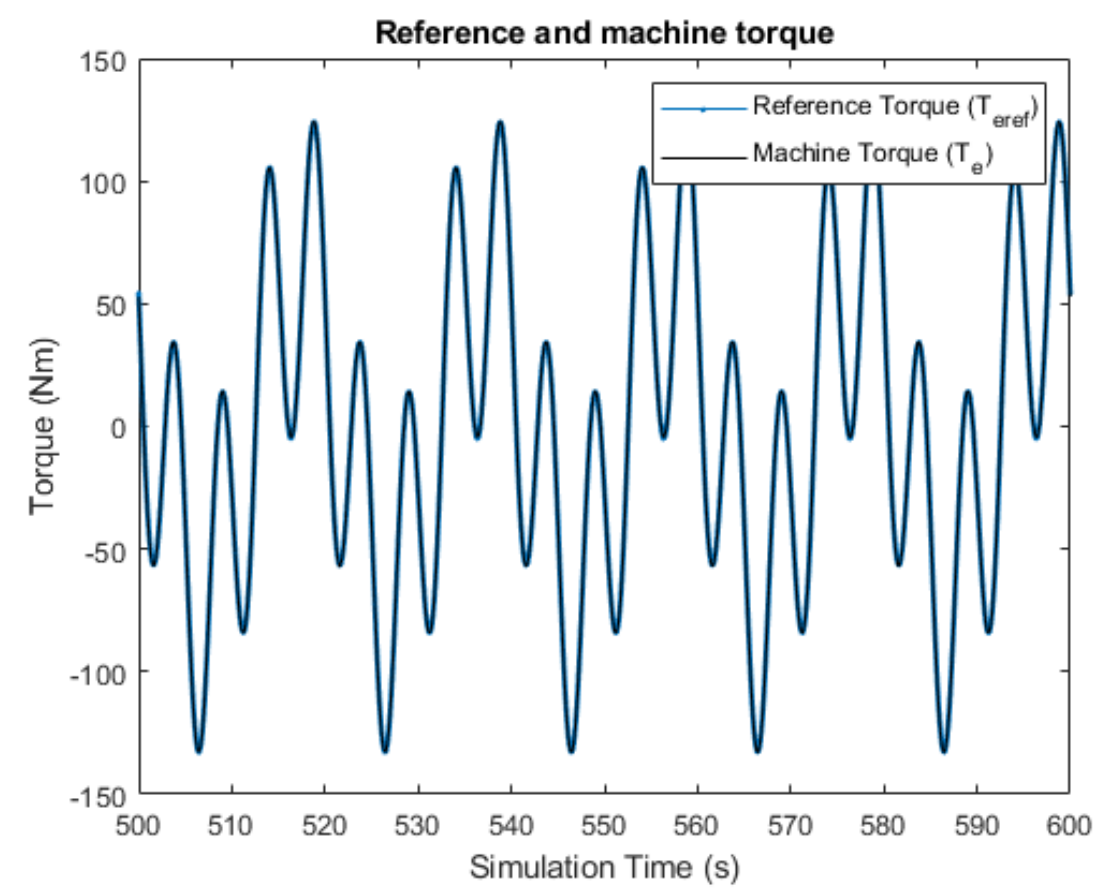

Figure 4.16: Reference and the actual torque of the DC machine - multifrequency

Figure 4.17 shows the modulation signal generated by the PI controller (section 2.3.2) for the inverter control. The current from the WEC drive $i_{\text {pto }}$ is shown in Figure 4.18 and it peaks at around $30 \mathrm{~A}$ for this case. The $\mathrm{i}_{\text {pto }}$ is always positive justifying that power extraction from the input wave is happening. It can also been observed that the output from the WEC drive increases as the input wave force increases. The frequency of these signals is twice the wave frequency period because of the positive and negative peaks of the input wave. 


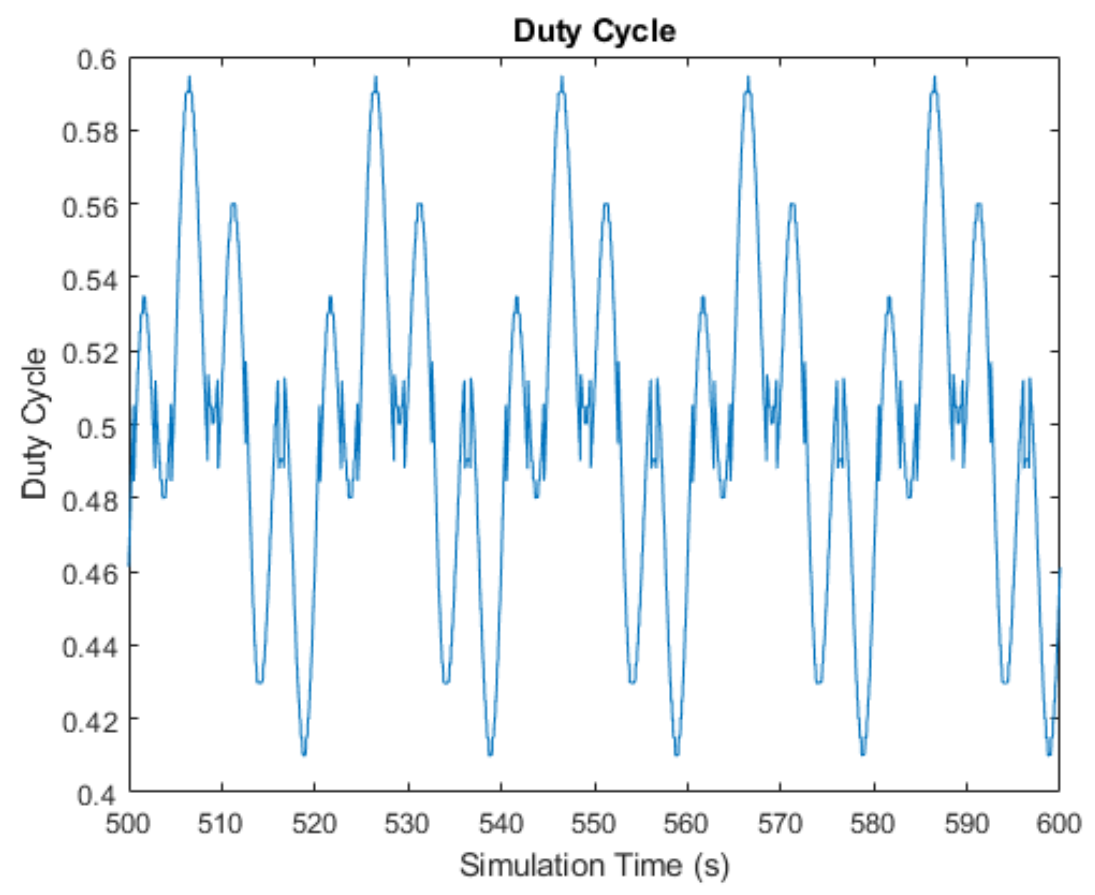

Figure 4.17: Modulation signal for inverter control - multi-frequency

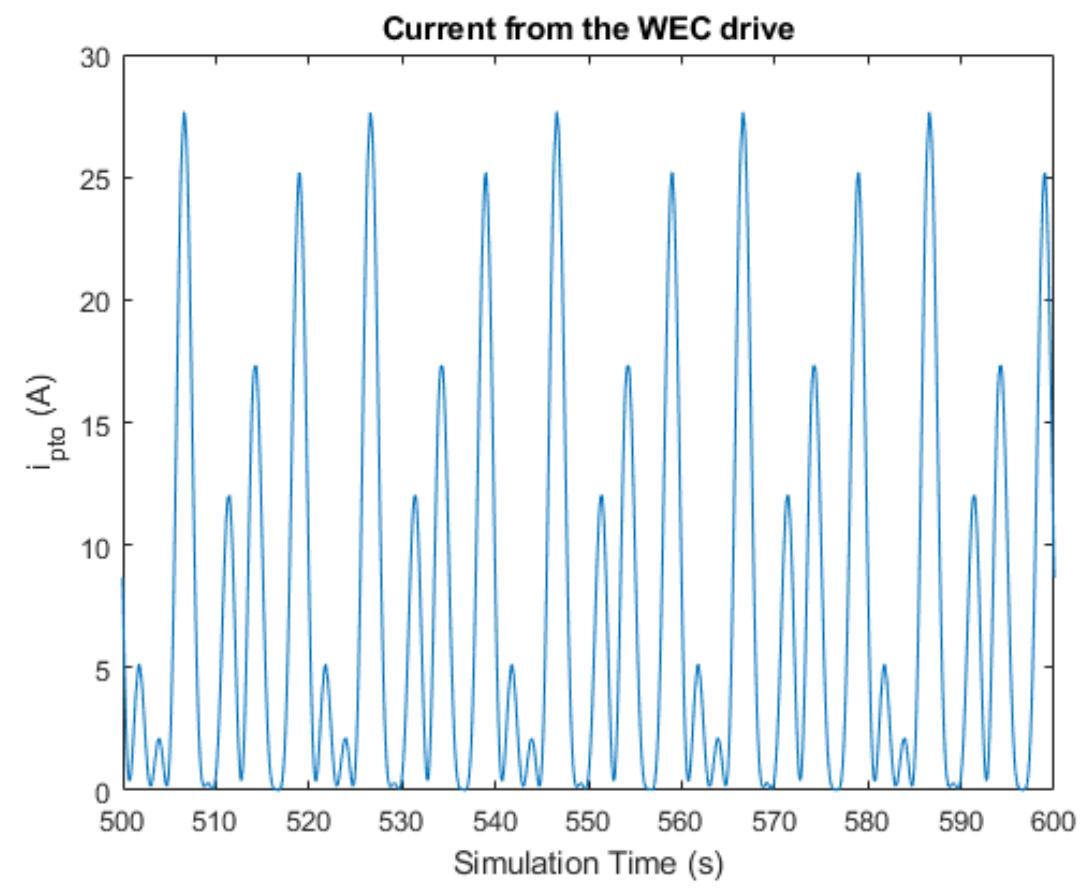

Figure 4.18: Current from the WEC drive - multi-frequency 
Figure 4.19 shows the bus voltage for this case. The bus voltage is achieving the reference bus voltage value at $200 \mathrm{~V}$ (section 2.3.3).

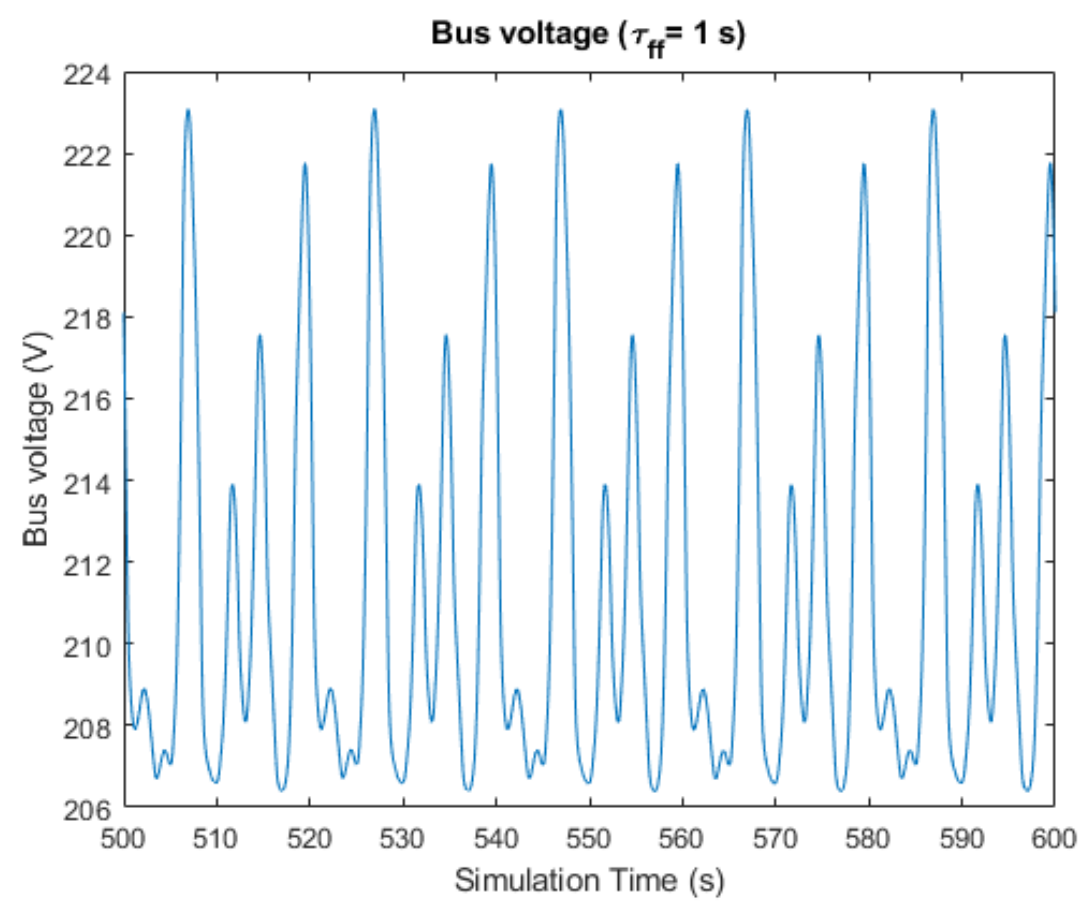

Figure 4.19: Bus voltage for $\tau_{f f}=1 \mathrm{~s}$ case - multi-frequency 
The power flow in the WEC system is illustrated in Figure 4.20. It can be observed that the mechanical power is the highest. As the power flows in the system from the mechanical end to the grid, several losses are happening due to the parasitic elements. The peak mechanical power generated for this case is close to $6500 \mathrm{~W}$ and it reduces to $4000 \mathrm{~W}$ at grid. It was observed that the losses are comparatively high for the multi-frequency wave case.

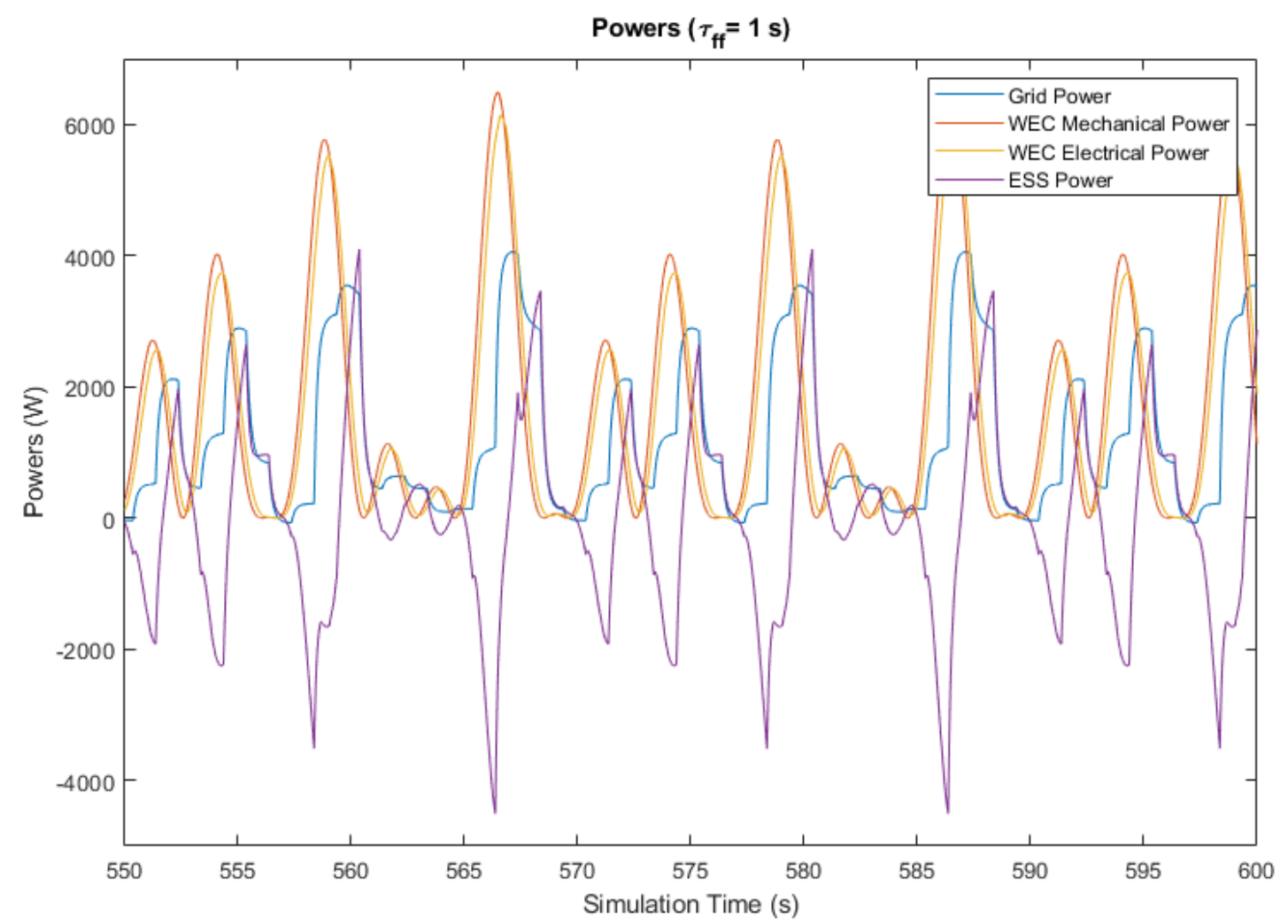

Figure 4.20: Powers in the WEC system for $\tau_{f f}=1 \mathrm{~s}$ - multi-frequency 
Figure 4.21 shows the current flows in the WEC system for multi-frequency wave case. It can be observed that when the demand from the grid is low, ESS is charging using the WEC drive current and vice-e-versa.

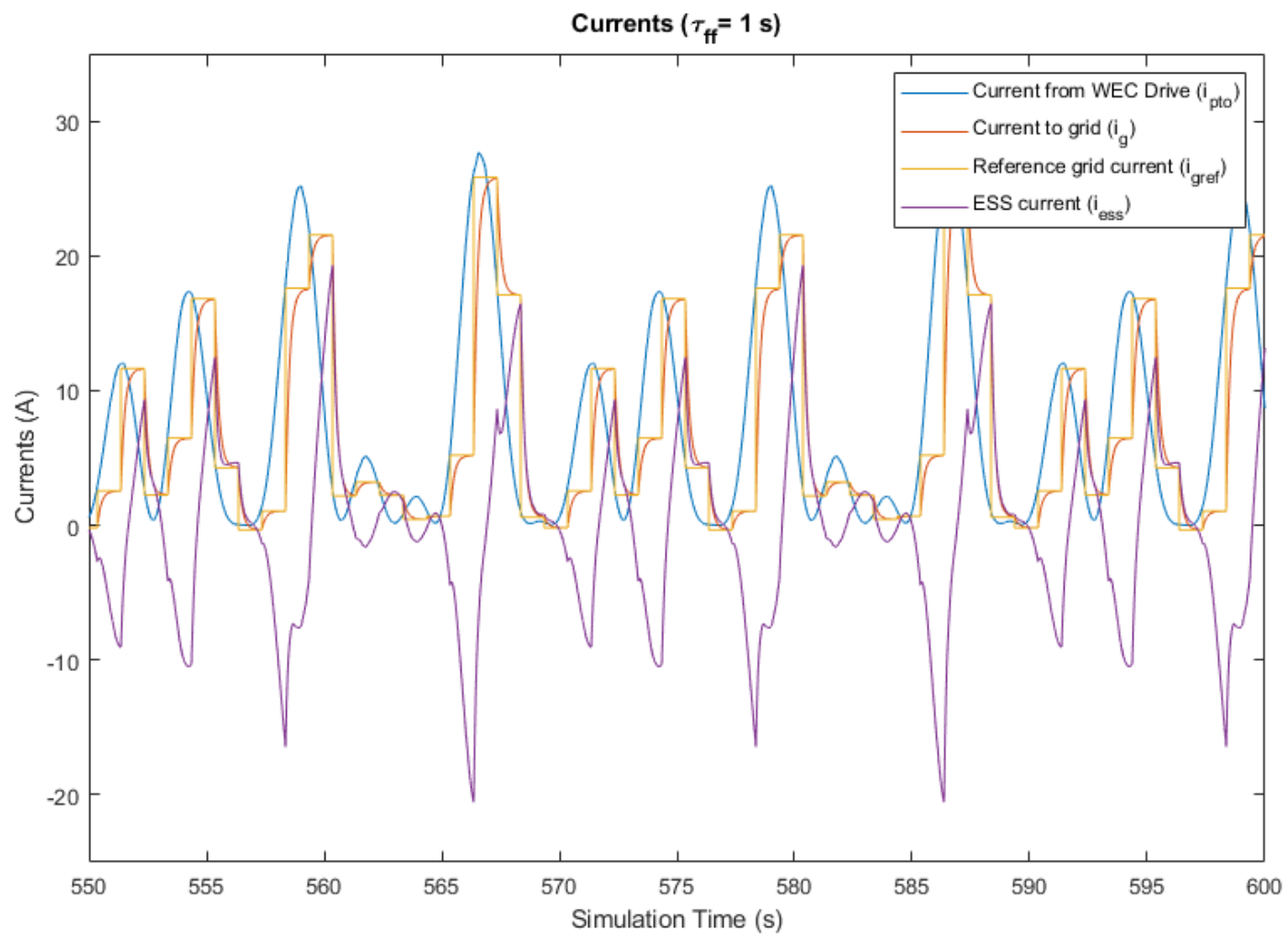

Figure 4.21: Currents in the WEC system for $\tau_{f f}=1 \mathrm{~s}$ - multi-frequency

The efficiency of the system for this case can be computed as

$$
\eta=\frac{\text { Average Grid Power }}{\text { Average Mechanical Power }}=\frac{1254.3}{1662.5}=75.45 \%
$$

The efficiency of the system during the multi-frequency test was observed to be lower 
due to higher losses as compared to the single frequency test. 


\subsection{Operating conditions of current model based on the update rate}

As mentioned earlier in section 2.3.3, the update rate is an important parameter to be explored, and a zero-order hold was used to simulate it. To study the effect of the update rate on the system, the WEC was run with the single frequency wave (section 4.1.1) for different update rates.

The wave force for the presented case $\left(\mathrm{F}_{w}\right)$ is $5000 \mathrm{~N}$ and the wave period is $20 \mathrm{~s}$. Figure 4.22 shows the trend of the bus voltage with respect to (w.r.t) to update rates.

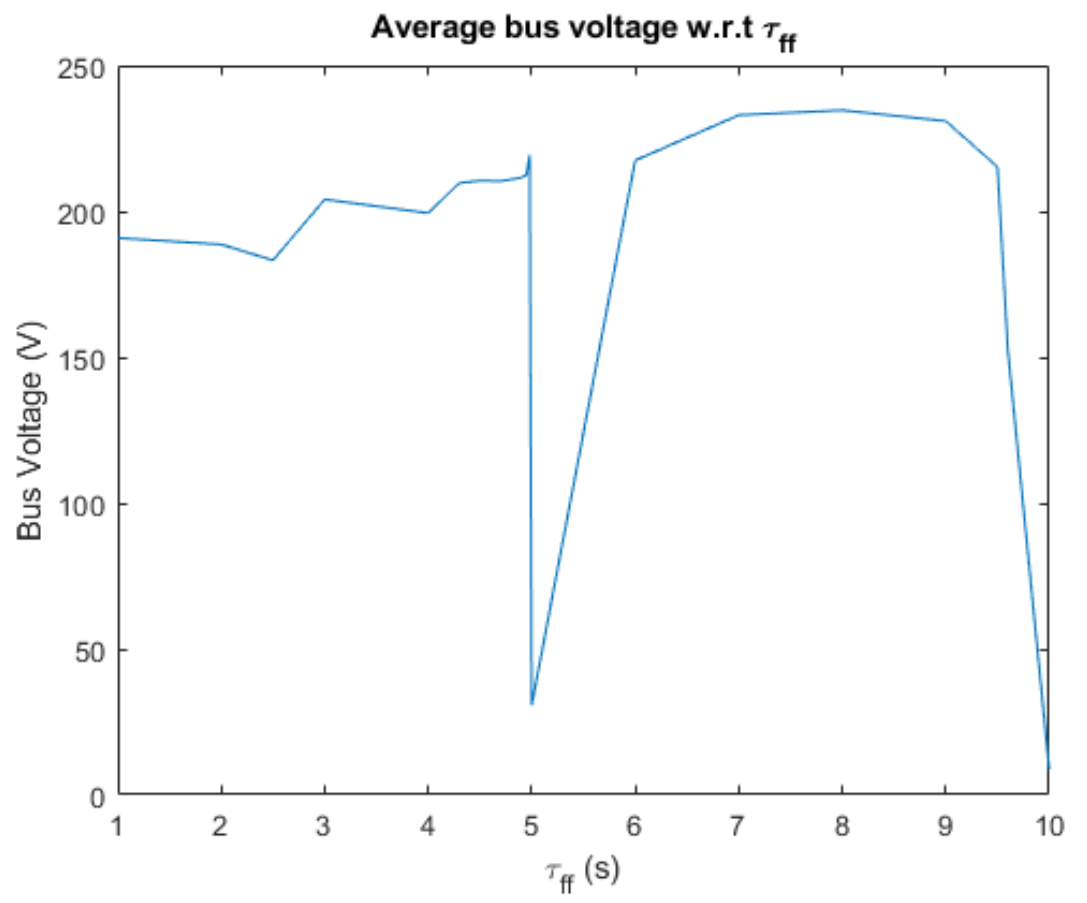

Figure 4.22: Bus voltage trend w.r.t update rate - $20 \mathrm{~s}$ wave period 
It was observed that the system was not achieving the reference bus voltage and reaching steady state for the cases where $\tau_{f f}=5 \mathrm{~s}$ and as the update rate reaches close to $10 \mathrm{~s}$. For all the other cases, the bus voltage achieves the reference bus voltage (Figure 4.22).

The variation observed here can be due to the limitation of the system while updating the grid reference current using the zero order hold. These probable reasons for the trends have been mentioned in detail later in section 4.2.1.

To validate that the result at $\tau_{f f}=5 \mathrm{~s}$ is not an outlier, data runs were done at several $\tau_{f f}$ 's close to $5 \mathrm{~s}$. Data was acquired for $\tau_{f f}$ of $4.3,4.5,4.7,4.9,4.95$ and 4.98 s. For all these cases, the system was attaining steady-state but, it was observed that as the update rate increases the variation in average bus voltage suddenly increases after $4.95 \mathrm{~s}$ and then dips at $5 \mathrm{~s}$. So, this shows that the system does not achieve steady state in this case. Similar trend is seen after 9.5 s. (Figure 4.23). 


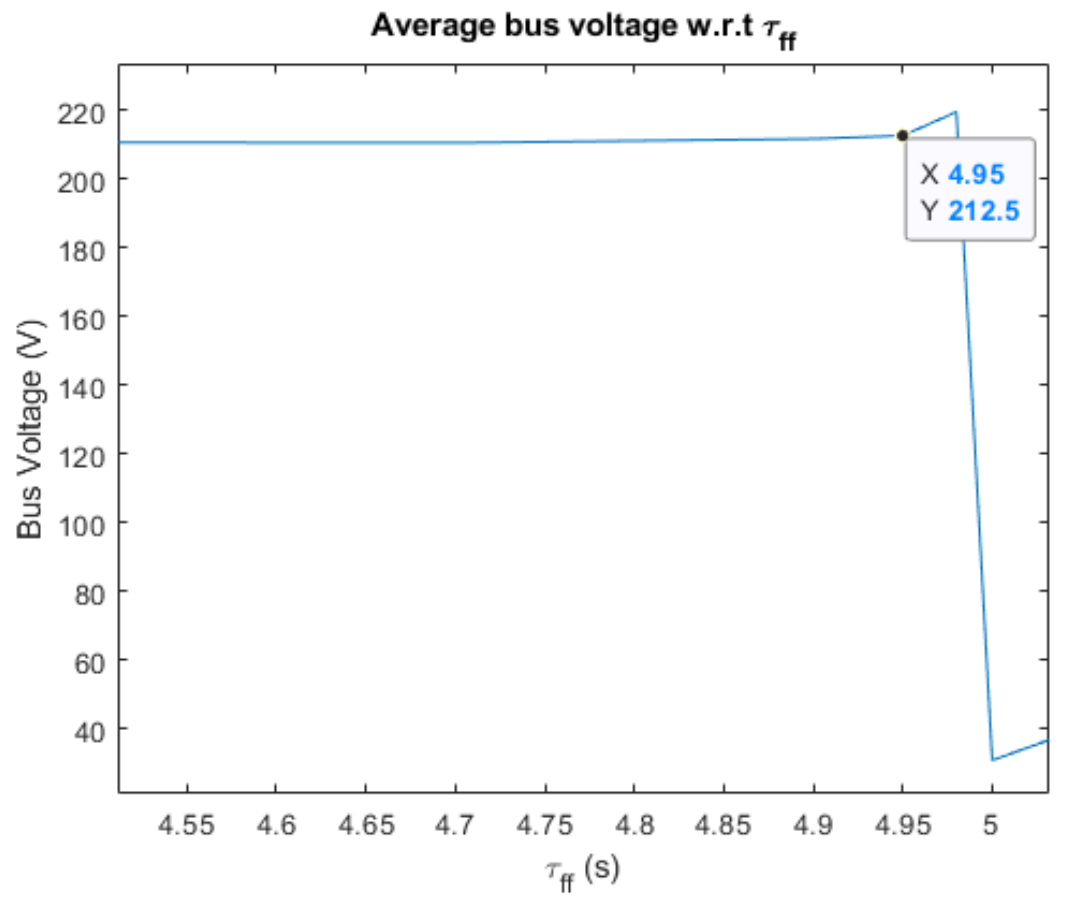

Figure 4.23: Bus voltage trend w.r.t update rate close to $5 \mathrm{~s}-20 \mathrm{~s}$ wave period

As the update rate increases, the system efficiency is reducing (Figure 4.24). The maximum efficiency at $81.51 \%$ was observed at the update rate of $2.5 \mathrm{~s}$. The efficiency is seen to be reduced after $4.95 \mathrm{~s}$ (Figure 4.25) because the system is not in steady state as it approaches to $5 \mathrm{~s}$ as seen earlier due to the operating limitation (section 4.2.1). 


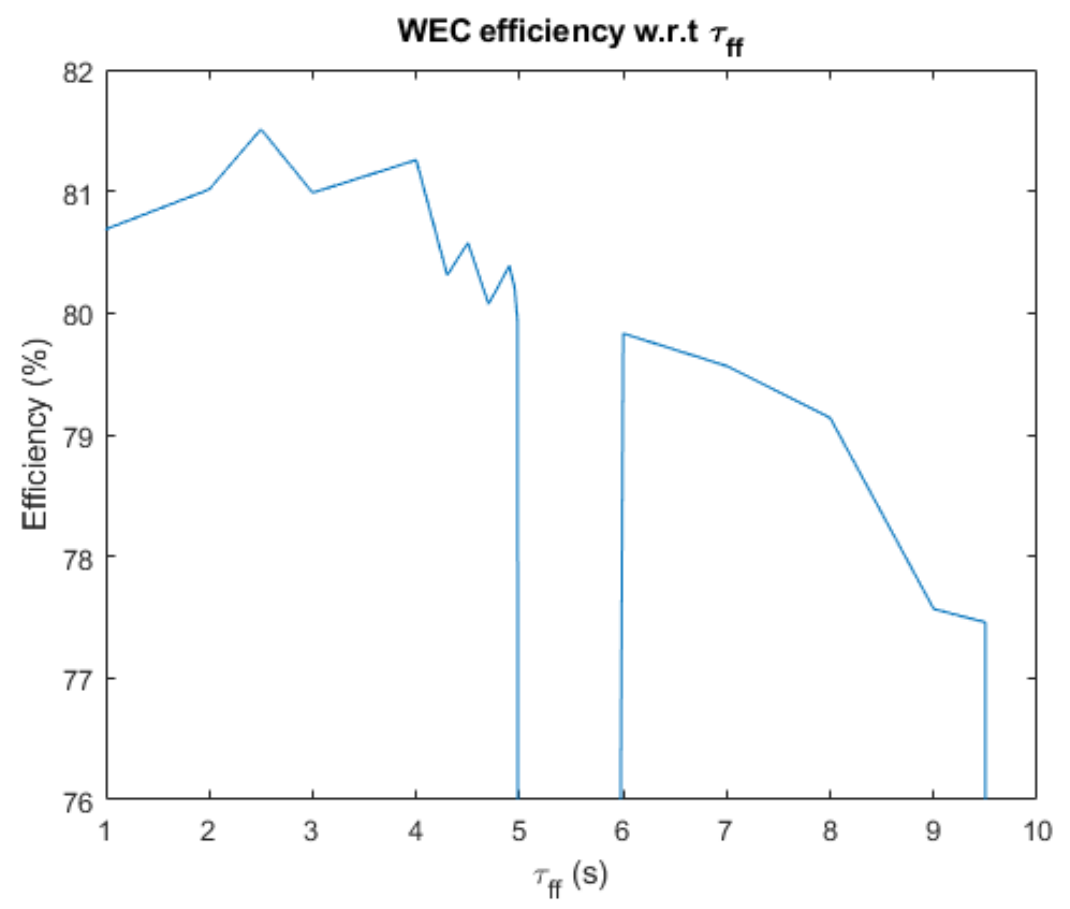

Figure 4.24: Efficiency w.r.t update rate - 20 s wave period

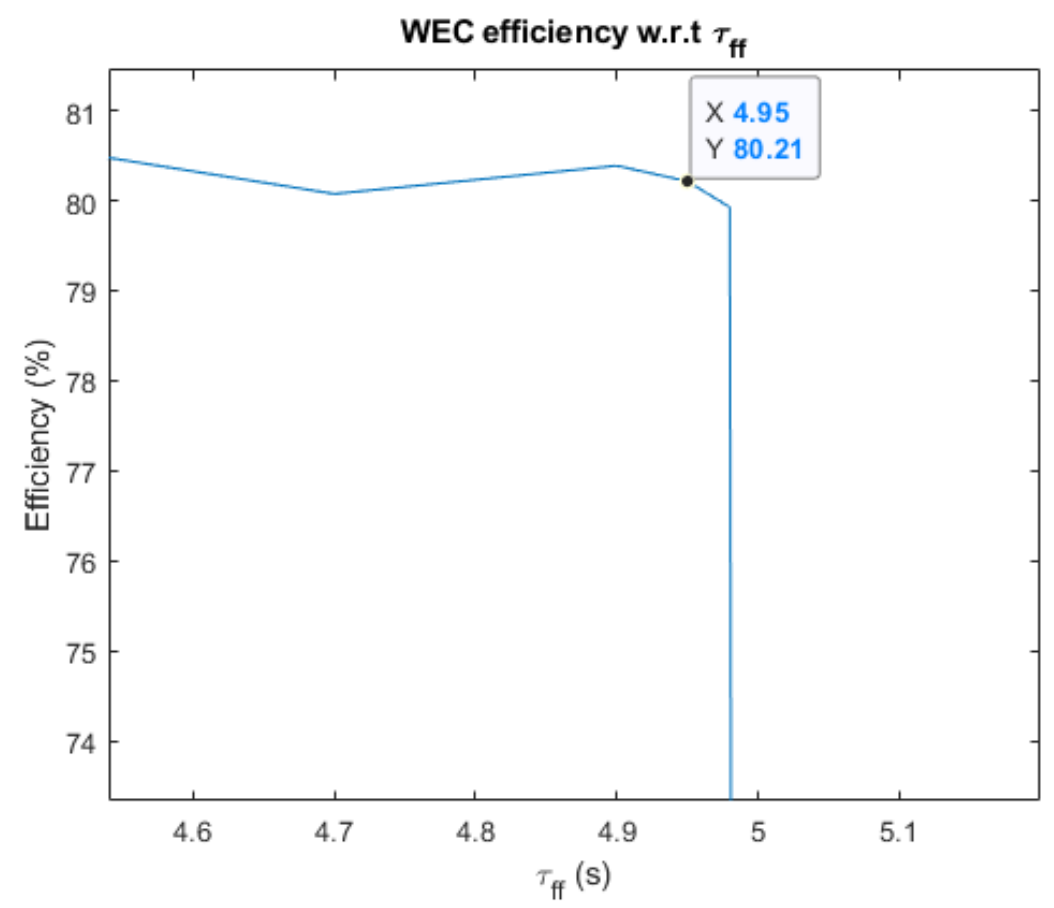

Figure 4.25: Efficiency w.r.t update rate close to $5 \mathrm{~s}-20 \mathrm{~s}$ wave period 
At higher update rates, the ESS power and energy are higher. This indicates that the ESS capacity should be higher because as the update rate increases, during the grid current update, the power contributed by the ESS to the grid needs to be higher (Figures 4.26 and 4.27). It should be noted that similar variations at update rate close to $5 \mathrm{~s}$ can be seen because it is an operating condition encountered in the system configuration.

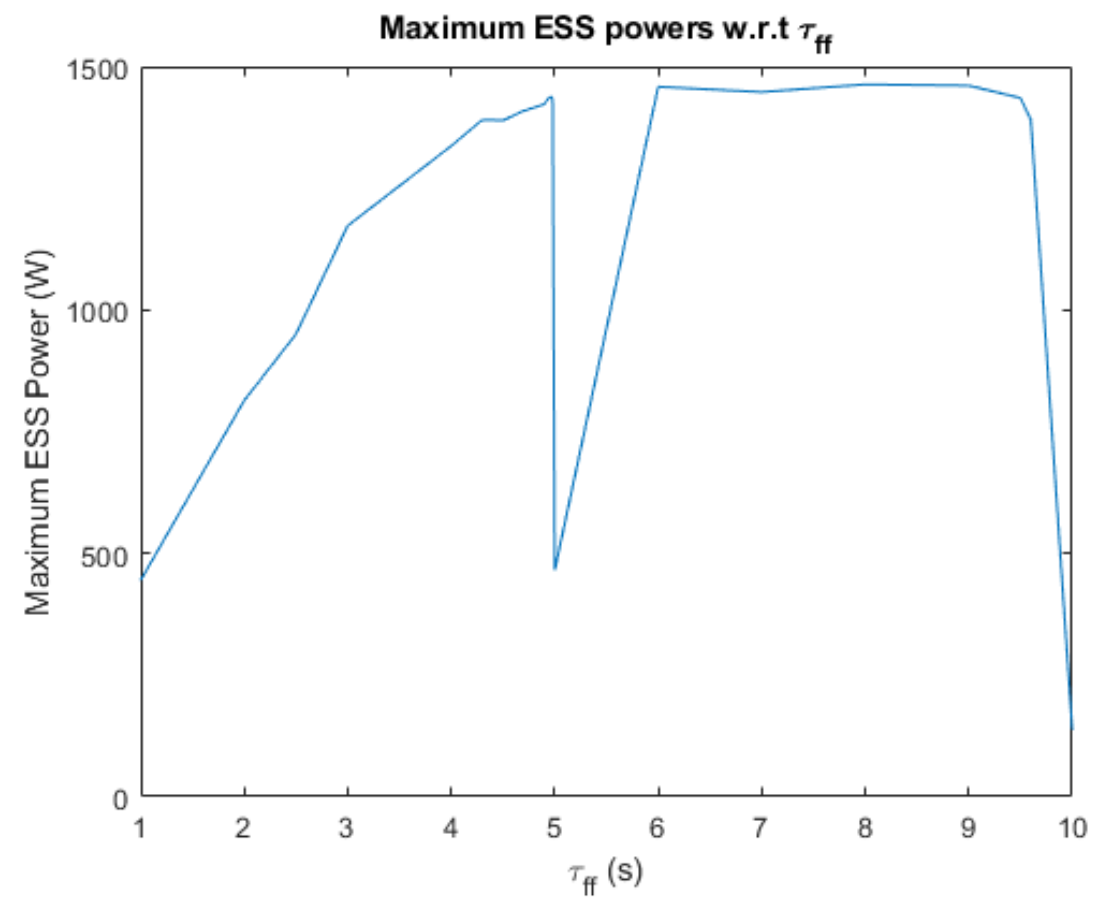

Figure 4.26: Max ESS power w.r.t update rate - 20 s wave period 


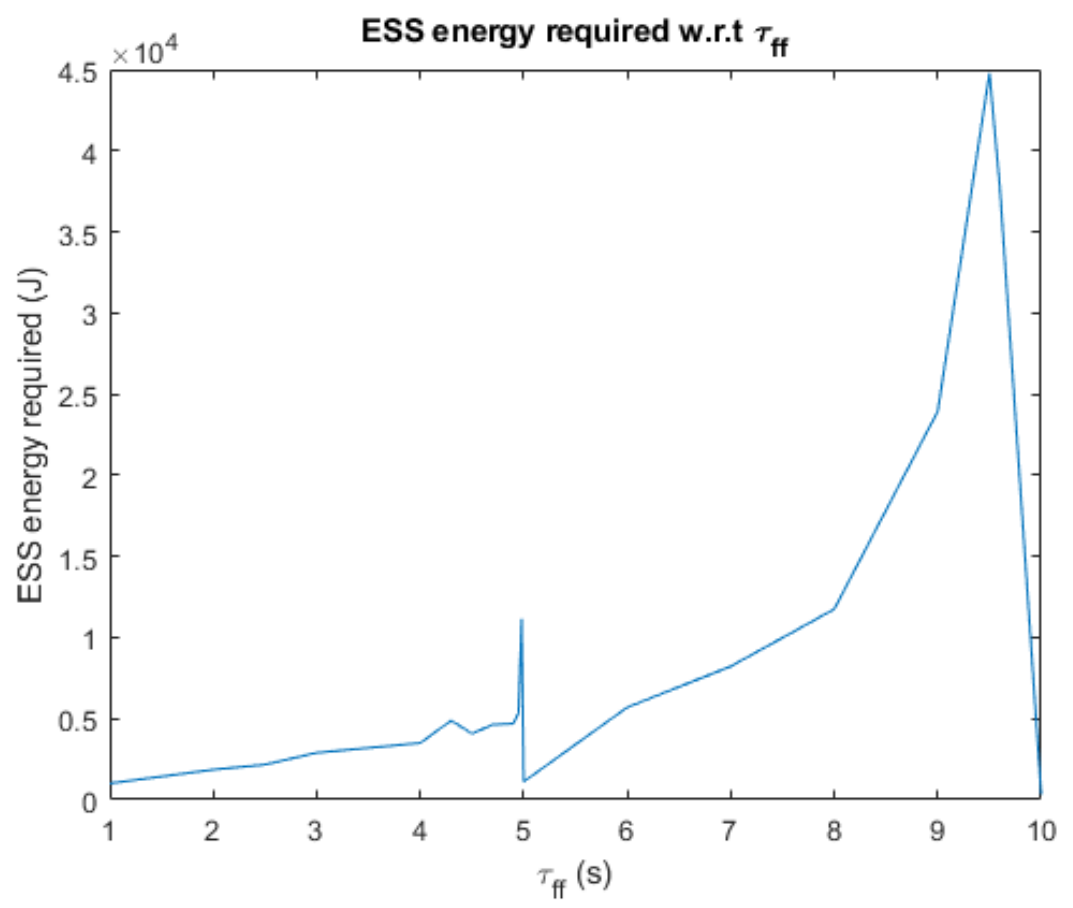

Figure 4.27: ESS energy required w.r.t update rate - 20 s wave period

\subsubsection{Discussions about the operating condition of the cur- rent model}

The update rate is simulated using a zero-order hold as mentioned earlier. The grid reference current is computed in real-time using (2.24) and the zero-order hold samples through the data in real-time to set and hold a value for $\tau_{f f}$ s. But, when the update rate is a multiple of the wave period, due to sampling at the same point, the grid reference current value will be the same as shown in Figure 4.28 and hence, the power export will be low always though there is enough WEC drive current. This condition is a limitation in the present system configuration and needs to be explored 
further.

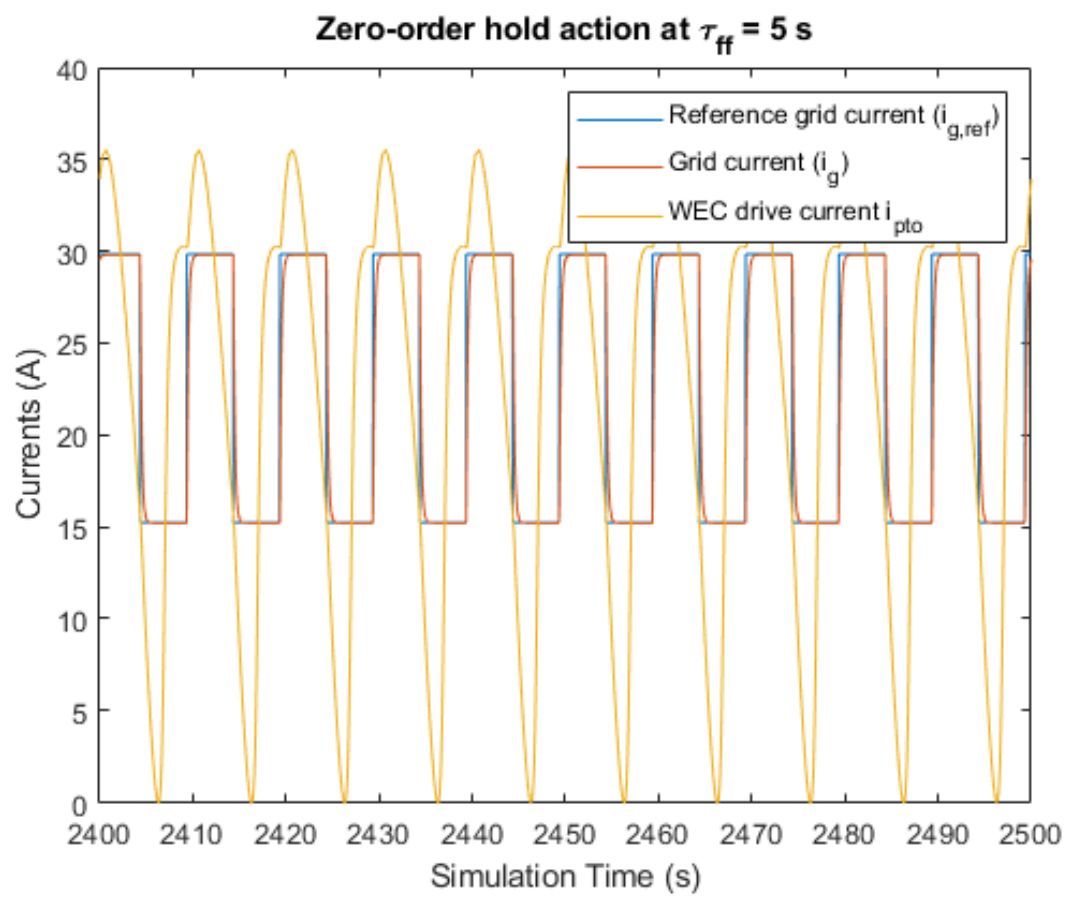

Figure 4.28: Currents at $\tau_{f f}=5 \mathrm{~s}$

It was also observed that the system does not attain steady state when the update rate approaches

$$
\tau_{f f} \rightarrow \frac{\text { Wave period }}{2}
$$

This can be explained using the Nyquist criterion. As an update rate is basically sampling a signal, the sampling frequency should be at least twice the wave frequency for proper reconstruction.

When there are multi-frequency waves, the possibility of periodicity significantly reduces. Hence the observation about the stability based on the update rate due to 
sampling may be less relevant when there are multiple frequency components in the wave as encountered in real-world scenarios. 


\subsection{ESS energy requirement}

Figure 4.29 shows the ESS energy trend at steady state for both single and multifrequency wave tests at update rate $\tau_{f f}=1 \mathrm{~s}$. During the runs, the ESS was modeled as a supercapacitor. The supercapacitor ratings were $\mathrm{C}=1 \mathrm{~F}$ and $\mathrm{R}=0.2 e^{-3} \Omega$.

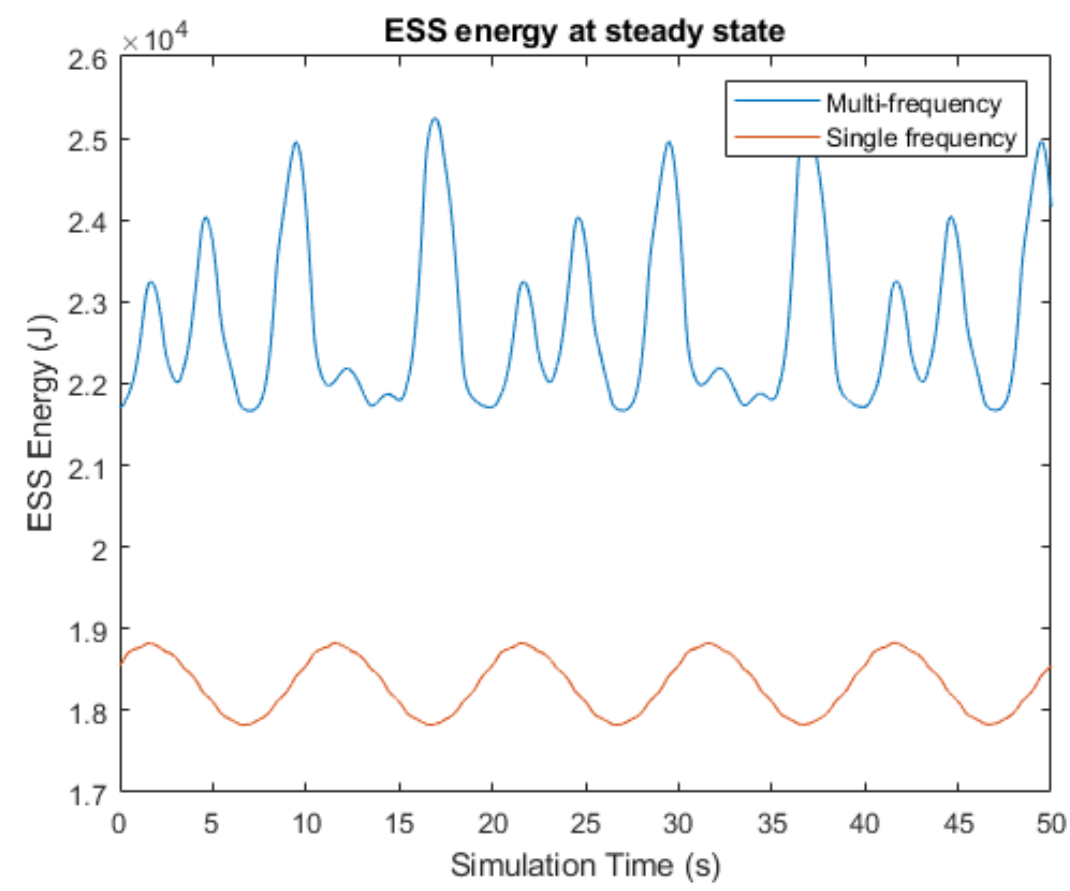

Figure 4.29: Comparing ESS energy for single and multi-frequency tests

ESS energy required during the single frequency wave test for a wave force $\left(\mathrm{F}_{w}\right)$ is $5000 \mathrm{~N}$ and the wave period is $20 \mathrm{~s}$ at the update rate of $1 \mathrm{~s}$ was $1004.2 \mathrm{~J}$.

ESS energy required during the multi-frequency wave test for the wave forces of $\mathrm{F}_{w 1}=5000 \mathrm{~N}$ and $\mathrm{F}_{w 2}=3000 \mathrm{~N}$ and wave periods being 20 and $5 \mathrm{~s}$ respectively for 
an update rate of $1 \mathrm{~s}$ was $3585.5 \mathrm{~J}$.

It was observed that the ESS requirement for these cases were low. But, as the wave force increases, the ESS energy required also increases. 


\section{Chapter 5}

\section{Conclusion and Future Work}

A WEC model was developed, and a few HIL simulations were run to validate the model's working. The modeled system behaves reasonably well for single and multifrequency waves. The efficiency of the system for the single frequency and multifrequency test at update rate of $1 \mathrm{~s}$ was found to be $80.69 \%$ (4.2) and $75.45 \%$ (4.4) respectively.

The effect of the update rate on the WEC behavior for a single frequency wave was explored. The behavior exhibited a few variations when the update rate value was approaching half the wave period. It can be explained using Nyquist criterion as the sampling frequency should be at least twice the wave frequency for proper reconstruction of the grid reference current. Similarly, the system also exhibits a 
limitation when the update rate is a multiple of the wave period probably due to periodicity in a single-frequency wave case. The limits and operating condition of the system needs further exploration.

A comparison of ESS energy requirement for both single and multi-frequency waves was presented. The ESS requirements of the system were found to be small in these preliminary tests. Further exploration in terms of multi-frequency tests and the effect of ESS on efficiency needs to be explored.

The future scope of the work is vast. This model can act as a starting point for all the studies regarding any WEC component. These improvements can be effortlessly integrated into this model, tested, and validated using the HIL devices. Modeling and design is the most important paramater to get started with HIL testing of any system. The systematic modeling of the system with appropriate I/O calibration is significant. Testing of these systems can be done on different scales from validating the model using HIL devices to replacing the individual sub-systems with hardware. 


\section{References}

[1] S. Kolosok, I. Myroshnychenko, H. Mishenina, and I. Yarova, "Renewable energy innovation in europe: Energy efficiency analysis," in E3S Web of Conferences, vol. 234. EDP Sciences, 2021, p. 00021.

[2] J. Dashwood, "4. the outlook for energy: A view to 2040," Australia's Energy Options: Renewables and efficiency, p. 45, 2012.

[3] F. Taveira-Pinto, G. Iglesias, P. Rosa-Santos, and Z. D. Deng, "Preface to special topic: marine renewable energy," Journal of Renewable and Sustainable Energy, vol. 7, no. 6, p. 061601, 2015.

[4] "Global status report 2021," https://www.ren21.net/wp-content/uploads/2019/| 05/GSR2021_Full_Report.pdf, REN 21.

[5] D. Clemente, P. Rosa-Santos, and F. Taveira-Pinto, "On the potential synergies and applications of wave energy converters: A review," Renewable and 
Sustainable Energy Reviews, vol. 135, p. 110162, 2021. [Online]. Available: https://www.sciencedirect.com/science/article/pii/S1364032120304536

[6] M. Bacic, S. Neild, and P. Gawthrop, "Introduction to the special issue on hardware-in-the-loop simulation," Mechatronics, vol. 19, no. 7, pp. 1041-1042, 2009.

[7] R. Isermann, J. Schaffnit, and S. Sinsel, "Hardware-in-the-loop simulation for the design and testing of engine-control systems," Control Engineering Practice, vol. 7, no. 5, pp. 643-653, 1999. [Online]. Available: https: //www.sciencedirect.com/science/article/pii/S0967066198002056

[8] H. K. Fathy, Z. S. Filipi, J. Hagena, and J. L. Stein, "Review of hardware-inthe-loop simulation and its prospects in the automotive area," in Modeling and simulation for military applications, vol. 6228. International Society for Optics and Photonics, 2006, p. 62280E.

[9] "Documentation - typhoon hil," https://www.typhoon-hil.com/documentation/.

[10] W. W. Weaver, D. G. Wilson, A. Hagmuller, M. Ginsburg, G. Bacelli, R. D. Robinett, R. Coe, and Budi, "Super capacitor energy storage system design for wave energy converter demonstration," in 2020 International Symposium on Power Electronics, Electrical Drives, Automation and Motion (SPEEDAM), 2020, pp. $564-570$. 
[11] W. W. Weaver, A. Hagmuller, M. Ginsburg, D. G. Wilson, G. Bacelli, R. D. Robinett, R. Coe, and B. Gunawan, "Wec array networked microgrid control design and energy storage system requirements," in OCEANS 2019 MTS/IEEE SEATTLE. IEEE, 2019, pp. 1-6.

[12] D. Wilson, G. Bacelli, R. G. Coe, D. L. Bull, O. Abdelkhalik, U. A. Korde, and R. D. Robinett III, "A comparison of wec control strategies," Sandia National Laboratories Tech. Rep. SAND2016-4293, vol. 10, p. 1431291, 2016.

[13] "Implement zero-order hold sample period - simulink," https://www.mathworks. com/help/simulink/slref/zeroorderhold.html. 